\title{
Risk allocation and the costs and benefits of public-private partnerships
}

\author{
Elisabetta Iossa* \\ and \\ David Martimort**
}

We study the agency costs of delegated public service provision, focusing on the link between organizational forms and uncertainty at project implementation. We consider a dynamic multitask moral hazard environment where the mapping between effort and performance is ex ante uncertain but new information may arise during operations. Our analysis highlights the costs and benefits that bundling planning and implementation - as under public-private partnerships - can bring in terms of project design and operational costs under various scenarios, possibly allowing for asymmetric information, moral hazard and renegotiation. It also shows that relying on private finance enhances the benefits of bundling only if lenders have enough expertise to assess project risks.

\section{Introduction}

Over the last twenty years, a major trend in both developed and developing countries has been an increasing level of delegation to the private sector for the provision of public services. Not only have traditional services such as transport, energy and gas been increasingly privatized, but new or more complex services have been contracted out for which there is no precedent in the private sector. Europe for example is experiencing this with the delegation of prisons operations, of school design and maintenance, of new methods for waste disposal such as recycling plants, and with an increasing use of concessions for toll roads, rail, ports, and bridges.

The completion of most of these public services requires two main phases: a planning stage where the project is designed, and an implementation stage where the project is executed. Under a public-private partnership (PPP), the supplier takes responsibility at both stages: it builds the

*DEF, University of Rome Tor Vergata CEPR CMPO and EIEF; Elisabetta.Iossa@uniroma2.it.

**Paris School of Economics-EHESS; david.martimort@parisschoolofeconomics.eu.

For useful comments or discussions, we wish to thank Malin Arve, John Bennett, Bernard Caillaud, Jérôme Pouyet, Emile Quinet, Timo Välillä and seminar participants at ESNIE (Ajaccio, 2007), at the Congrès de l'Association Française d'Economie (Paris-Sorbonne, 2009), Université de Franche-Comté, the UBC P3 Project (2008, Vancouver), the International Conference Contracts, Procurement, and Public-Private Arrangements (Paris, 2011) and the XIII CEPR/JIE Conference on Applied Industrial Organization (Venice, 2011). Jim Hosek and two referees were instrumental in helping us to reshape our ideas on this project. We thank Perrin Lefebvre for exceptional research assistance. All errors are ours. Iossa gratefully acknowledges financial support from the Ministry of Education, University and Research (MIUR), PRIN grant 2008. 
infrastructure and provides the service. ${ }^{1}$ In transport projects for toll roads, ports and rail, the private provider typically recoups its infrastructure investment through charges to final users (concession model). In PPP hospitals, schools and prisons, where typically users do not pay, the public sector reimburses the firm through shadow fees (PFI model). In either case, public subsidies may help covering the initial investment.

Such delegation takes place in contexts plagued with agency costs, transaction costs, and contract incompleteness. Economic theory suggests that both moral hazard and adverse selection problems may arise in such context. At the planning stage, the agent must be motivated to better design the project. At the implementation stage, he must be incentivized to efficiently manage the project and use any information that might have been revealed during operations. This article studies how uncertainty at the implementation stage affects these costs of delegation, and derives implications for the optimality of PPP agreements.

Uncertainty is important not just because firms may be risk-averse, which leads to the classical moral hazard trade-off between risk and incentives. Uncertainty also affects the degree of contractual incompleteness that characterizes most complex projects. For example, when the U.K. public authority first outsourced the electronic monitoring services for the Home Detention Curfew (HDC) scheme in the mid 1990s, the service was without any precedent (Serco Institute, 2007). Similarly, when the U.K. National Audit Office (NAO) first reviewed the success of the three highly complex PPPs that were signed to finance and manage London's Underground system, and in spite of a period of "shadow running" to review arrangements and make adjustments, they found it "hard to determine whether [the measures were] easy or difficult to achieve, and whether they [were] sufficiently aggressive" (NAO, 2004).

$\square$ Overview. We consider a model of procurement in a dynamic multitask moral-hazard environment where the mapping between effort at the design stage and final performance is ex ante uncertain but new information may come along during operations. ${ }^{2,3}$ We compare a setting where a single agent is in charge of both planning and implementation with one where these tasks are allocated to two different agents. We start by considering the case of projects where uncertainty is pervasive in the sense that neither the public authority nor the contractor can predict ex ante all contingencies (productivity shocks) that may arise during operations. Incentives are provided through revenue-sharing agreements when users pay (concession model), or through service standards agreements when users do not pay (PFI model), and through an infrastructure quality index.

We show that incentives at the design stage are boosted under bundling because the firm internalizes the positive externality that a better design has on reducing its future costs of running the service. Effort at the operating stage increases and boosts revenues, or service standards for services where users do not pay. Bundling has the greatest benefits in terms of innovative design and lower costs when demand risk is low, when service standards can be measured precisely, when the infrastructure quality index is imprecise, and when the technology is flexible and easily adapts to unforeseen circumstances.

We then extend the analysis to projects where uncertainty is less pervasive and more complete contracting is possible, productivity shocks being verifiable ex post. This can be thought of as a metaphor for cases where sufficient past evidence is available to inform parties of what may arise during the operational stage. The contract will then also compensate the firm for adverse

\footnotetext{
${ }^{1}$ The DBFO model (Design, Build, Finance, and Operate), the BOT model (Build, Operate, and Transfer), and the BOO (Build, Own, and Operate) all feature bundling of building and operation in a single contract with a single firm (or a consortium of firms).

${ }^{2}$ This uncertainty distinguishes our approach from others in the literature. See Aghion and Tirole (1994) and Rosenkranz and Schmitz (2003) for incomplete contracting models of innovation with perfect knowledge of the mapping between research and development.

${ }^{3}$ Multitasking makes the analysis of PPPs quite specific compared with the general literature on privatization. See Sappington and Stiglitz (1987), Shapiro and Willig (1990), and the overviews by Shleifer (1998) and Martimort (2006).
} 
events beyond his control. This insurance improves the noise-to-signal ratio at the operating stage and eases the trade-off between risk and incentives. With a more efficient risk allocation, the advantages of bundling in terms of greater design effort and lower operational costs are boosted.

The lesson of these findings is that bundling certainly dominates when contracting takes place under symmetric (although possibly incomplete) information over productivity shocks. This stands in sharp contrast with what happens for complex projects where productivity risks are high but their realizations are private information of the firm at the operating stage. With asymmetric information, compensating the firm for adverse events beyond its control becomes more complex, as the operator might claim to be hit by a negative shock in order to receive a greater compensation. Inducing information revelation requires using low-powered compensations that leave little of the revenues of the services to the firm following such negative shock. Although it limits the firm's incentives to claim for such compensation, such a scheme kills incentives to boost revenues by exerting operating effort. Under bundling, the problem is exacerbated because the firm may under-deliver in the design stage and then blame the poor outcome in the operation stage on a bad productivity shock rather than a poor design. Preventing such strategic under-delivery calls for compensations that do not provide much insurance at the operating stage.

However, committing to such a scheme is not credible. Once the design is already chosen, there is scope to renegotiate compensations at the operating stage and provide more insurance. With renegotiation becoming ex post attractive, ex ante incentives to deliver a good design are further weakened. We show that when uncertainty on productivity shocks is high, compounding asymmetric information ex post, moral hazard and renegotiation results in contracts that might no longer insure the firm against productivity shocks beyond its control. Such lack of insurance may be so costly that the gain in terms of a better design that better internalizes externalities becomes insufficient to justify bundling. Unbundling then dominates.

In DBFO projects (Design, Build, Finance, and Operate), the bundling of design and implementation is accompanied by the use of private finance, which typically covers about $90 \%$ of project costs, the remaining $10 \%$ being equity. Although private finance is in general more costly than public finance, the due diligence carried out by the contractor's banks may sometimes stop contractors taking inappropriate risks. Lenders may indeed have the expertise to assess risks carefully, improving the quality of the business plans, and ensuring that contingency plans are in place to manage risks appropriately. Our article shows that should financiers have such expertise and should the public authority have not, private finance increases the value of a PPP. In the presence of high risks, this improvement can justify the higher cost of private capital. In particular, private finance helps reestablish the benefits of bundling when the lack of expertise of the public authority could favor unbundling. Indeed, practitioners do acknowledge that the record of conventional public sector procurement in assessing risk is not good (Leahy, 2005), and rating agencies such as MOODY's (2007) explicitly recognize the importance of the quality of the contractor's financial model — typically audited by lenders - to calculate operational risk in PPP projects. ${ }^{4}$

Evidence. Empirical observations confirm the importance of externalities across design and implementation for many projects. For example, the innovative design of PFI prisons in the United Kingdom was found to have brought cost saving of 30\% (NAO, 2003). The innovative design in PFI motorway projects was similarly found to reduce traffic disruption from maintenance, as well as lower costs, time, and raw materials. In line with our predictions, PPPs have also resulted in increased performances as uncertainty is reduced by growing experience. In the U.K. PPP housing sector, problems initially arose from the complexities in obtaining planning permissions for multiple sites and the difficulties in estimating costs for the refurbishment of properties at

${ }^{4}$ Lenders in PPP projects (directly or through independent consultants) typically undertake an audit of the financial model of the contractor, for example to ensure that the financial model has been prepared within accepted accountancy standards. 
the outset of procurement, but lessons were learned from pathfinder projects and the injection of public sector expertise (HM Treasury, 2006). In various countries, knowledge accumulation has also been favored by setting up dedicated centers of expertise on PPP projects (e.g., Central PPP Policy Unit in the Department of Finance in Ireland, the Unitá Tecnica della Finanza di Progetto in Italy, Partnership UK in the United Kingdom), and by diffusing best practices on risk assessment and risk allocation.

Our results also explain the skepticism on the use of PPPs for complex projects where risks are high and uncertainty is pervasive. In complex IT projects, the link between the effort the operator puts in handling the system and its performances is certainly more uncertain than in conventional IT systems. Given the peculiarities of each and every system, there is a significant informational advantage that the operator gets over the public authority. With the public authority unable to verify why software customization was more time-consuming than anticipated, the contractor will have to be responsible also for events beyond its control. For very complex projects, risk transfer becomes so costly that PPPs become unsuitable. The United Kingdom has indeed recommended against using PPPs for complex IT projects. Concerns have also been repeatedly expressed on the performance of PPPs in new sectors such as waste and recycling, where the cost of disposal may vary dramatically and no past experience may inform parties, and for complex and innovative clinical services where technology changes quickly and risks are high.

Our results suggest that renegotiation plays an important role in determining the costs and benefits of PPPs. In practice, given the length and the uncertainty surrounding those projects, PPP contracts have often been renegotiated. In the United Kingdom, renegotiations occurred in $33 \%$ of PFI projects signed by central government departments between 2004 and 2006. The changes amounted to a value of over $£ 4 \mathrm{~m}$ per project per year, equivalent to about $17 \%$ of the value of the project (NAO, 2007). Illustrative is also the case of specialized IT provision where the appropriate use of the facility involves continuous adaptation.

$\square \quad$ Literature review. Our model belongs to a burgeoning literature that discusses the costs and benefits of bundling tasks in contexts plagued with transaction costs, agency costs and contract incompleteness. That literature can roughly be decomposed into two trends which, although different in motivation and scope, share the common finding that bundling tasks is beneficial when contracting costs exhibit scope economies.

The first subset of the literature builds on the incomplete contracts and property rights paradigms. Hart (2003) presents a model where the sole source of incentives is asset ownership. A builder can perform two kinds of investment (productive and unproductive) which may both reduce operating costs, although only the productive investment raises the value of the service. Under traditional procurement, the builder cannot internalize the impact of his effort, neither on benefits nor on costs, and as a result implements too little of both investments. Under a PPP, the builder partly internalizes the impact of his productive investment whereas he still exerts too much of the unproductive one. ${ }^{5}$ Bennett and Iossa (2006) study the desirability of bundling and giving ownership to the investor. Innovations are noncontractible ex ante but verifiable ex post. Ownership gives right to the owner to decide whether to implement quality-enhancing or cost-reducing innovations proposed by the investor. The hold-up problem is less severe under a PPP, compared with traditional procurement, when there is a positive externality between building and managing assets.

Externalities between various production stages are also the focus of a branch of the agency literature, which, beyond the specific case of PPPs, addresses the benefits of bundling tasks in moral-hazard environments. In Martimort and Pouyet (2008), the agency trade-off between insurance and incentives is easier under a PPP when a better design also reduces operating

${ }^{5}$ Still using the property rights approach, Besley and Ghatak (2001), King and Pitchford (2001), and Francesconi and Muthoo (2006) analyze ownership for a public good.

(C) RAND 2012. 
costs. Providing incentives for lower costs also boosts incentives for a better design. ${ }^{6}$ Iossa and Martimort (2008) build on these insights, extending the analysis to cover other issues in PPPs, from contract duration, to private finance and regulatory risk. In this article, we significantly depart from those analysis by focusing on an environment where costs are nonverifiable and the synergy between design and implementation is uncertain.

Other benefits of bundling allowing for reciprocal effort supervisions, improved risk-sharing, or improved incentives in ongoing relationships have been found in various other agency contexts by Che and Yoo (2001), Choi (1993), Macho-Stadler and Perez-Castrillo (1993), Itoh (1993), and Ramakrishnan and Thakor (1991). ${ }^{7}$

Organization of the article. Section 2 presents our model. Section 3 analyzes optimal incentive schemes under unbundling and bundling in our basic scenario where uncertainty is pervasive and productivity shocks that may arise during the operational stage cannot be predicted ex ante. This section presents the benefits of bundling tasks. Section 4 considers more complete contracting environments, studying the case where shocks can be contracted upon, and showing that the benefits of bundling are boosted. Section 5 covers the central case where the firm has private information on the productivity shocks and shows that bundling may now be costly. Section 6 studies the costs and benefits of private finance and how the financier's expertise can help to recover all benefits of bundling. Section 7 summarizes our findings and provides alleys for further research. Proofs are relegated to an Appendix.

\section{The model}

- We consider the following public procurement context: A public authority (the principal) relies on a private firm or consortium (the agent) to provide a service. Examples of such delegation include transportation, water production and sanitation, waste disposal, clinical and educational services, and so forth. In such settings, providing the service also requires designing and building an infrastructure. This delegation is modeled as a multitask problem.

In the sequel, we discuss the rationale for relying on a PPP (bundling) rather than adopting a more traditional procurement model. With such traditional contracting, the principal first buys the infrastructure from a given builder and then selects an operator. We thus investigate whether the two tasks of respectively designing/building the assets and operating them should be bundled and performed by the same contractor (a consortium) or instead whether they should be unbundled and undertaken by two separate firms (a builder and an operator).

Technology. Investing in the infrastructure initially costs $I$. In a first building stage, the builder chooses a design. By exerting effort $a$ (or, by making some investment in the quality of the infrastructure), the contractor improves the quality of the project and raises its social value. Investing $a$ has a monetary cost $\frac{a^{2}}{2}$ which is borne by the firm.

For services where users pay (concession model), the stochastic revenues from the service are defined as

$$
R=e+\zeta,
$$

where $e$ is the operating effort and $\zeta$ is a shock normally distributed with zero mean and variance $\eta^{2}$. The effect of $e$ on $R$ captures for example the higher demand from users of transport services when service reliability, on-the-train services, or the efficiency of the ticketing system are higher. One can interpret $\zeta$ as a demand shock. In transport concessions, for example, even when there is a

\footnotetext{
${ }^{6}$ See Holmström and Milgrom (1991). In Martimort and Pouyet (2008), ownership imperfectly aligns incentives. To a large extent, the important issue is not who owns the asset but instead whether tasks are bundled or not.

${ }^{7}$ The benefits of bundling tasks have also been investigated in adverse selection environments. See Baliga and Sjöström (1998), Baron and Besanko (1992, 1999), Gilbert and Riordan (1995), Laffont and Martimort (1998), Dequiedt and Martimort (2004), Mookherjee and Tsugamari (2004), and Severinov (2008).
} 
reasonable level of confidence in forecasts, revenues can be dramatically affected by competition from other modes or facilities, by levels of economic activity, and by the price of inputs (e.g., fuels).

To simplify our exposition, we shall use $R$ interchangeably to denote also the benefit from the service for those services where users do not pay (PFI model). Here, $e$ captures for example the operational efficiency of hospitals, the attitude of prisons staff toward inmates, or the quality of education and management in schools, whereas $\zeta$ captures uncertainty affecting social benefits.

The operating effort $e$ improves revenues but is costly for the operator. This cost can be a disutility of effort counted in monetary terms or a true operating cost in which case that cost is nonverifiable. It is expressed as $\frac{\mu}{2}(e-a-\theta)^{2}$ where $a$ is the design effort, $\theta$ is a productivity shock and $\mu$ is a parameter that reflects the flexibility of the technology at the operating stage; $\mu$ being greater as the technology becomes less flexible. Except in Sections 4 and 5, we shall assume that $\theta$ is also normally distributed with zero mean and variance $\vartheta^{2}$. The operator chooses the effort $e$ ex post, i.e., once he already knows $\theta$. This simple formulation allows us to capture how the firm adapts its operational efforts to productivity shocks.

Some justifications for those assumptions are in order. First, a greater design effort $a$ reduces the cost of operating effort. For example, a better design simplifies operations, or a better transport infrastructure reduces maintenance effort. Second, the random variable $\theta$ captures the uncertainty that may characterize the mapping between design and operation. Exogenous events or productivity shocks may affect operations so as to increase or reduce the cost of operating effort, for any given project design. Third, the variance of $\theta, \vartheta^{2}$, captures operational (cost) risk, namely the effect on the cost of operations of exogenous factors, such as force majeure events, inflation, or changes in input prices. ${ }^{8}$

Contracts and organizational forms. The revenue $R$ is verifiable and can thus be contracted upon. In transport projects, for example, revenues can be verified through electronic ticket systems, whereas in energy projects they can be specified through computerized billing systems, and revenue sharing agreements between the public authority and the contractor are widely employed. For projects where users do not pay (PFI model), service standards $(R)$ are verified using key performance indicators and audit, complaints received, and user satisfaction surveys. ${ }^{9}$ Although $R$ is verifiable, the public authority cannot disentangle the impact of outside variables $\zeta$ and the effect of operational effort $e$ on revenues. ${ }^{10}$

Costs incurred both at the design and operation stages are nonverifiable. ${ }^{11}$ However, the principal has also at his disposal a contractible quality index $Q$ to check the quality of the infrastructure. This quality index is directly related to the first-stage effort and writes as

$$
Q=a+\epsilon,
$$

where the error term $\epsilon$ is again normally distributed with zero mean and variance $\sigma^{2} .{ }^{12}$

Contracts based on revenues and quality index can be used to regulate the services. ${ }^{13}$ Following Holmström and Milgrom (1987, 1991), we assume that contracts are linear in

\footnotetext{
${ }^{8}$ Our modeling is equivalent to assuming that $a$ positively affects the mean of the second-period productivity shock while leaving variance unchanged.

${ }^{9}$ See the study by PUK (2008). Contracts specify performance measures (typically 30/40; Serco, 2007) and the number of points that each underperformance/overperformance attracts. The accrued number of performance points is then used to adjust the contractor's payment at the end of a period.

${ }^{10}$ For example, the punctuality of trains and transport services is affected by weather or traffic conditions and the operational efficiency of contractors, but the effects cannot be perfectly disentangled.

${ }^{11}$ The nonverifiability of costs is a key feature of complex projects like PPPs. This is especially true in developing countries, as noticed by Laffont (2005) and Estache and Wren-Lewis (2009).

${ }^{12}$ This quality index can be viewed as a set of specifications of the projects above some minimal acceptable quality.

${ }^{13}$ For instance, infrastructure quality indicators in the contract for London Underground included some variables directly related to design like (i) capability, a measure of the capacity of the infrastructure, capturing the average journey time; and (ii) availability, a measure of the reliability of rolling stock, signaling, track, and station-based equipment (NAO, 2004).
} 
the contracting variables and we refer to the slopes of those contracts as the incentive intensities.

Under unbundling, we assume that the operator does not observe the builder's effort but perfectly anticipates its equilibrium value. For instance, many dimensions of the design cannot be easily assessed by the operator which in turn justifies that operating costs themselves are not verifiable. The builder is rewarded as a function of the quality index and operates under a linear scheme based on that index only:

$$
t_{B}(Q)=\alpha_{B}+\beta Q .
$$

The operator keeps a share of the operating revenue and also operates under a linear scheme:

$$
t_{O}(R)=\alpha_{O}+\gamma R \text {. }
$$

The fixed payments $\alpha_{B}$ and $\alpha_{O}$ can be interpreted either as an upfront fee paid at the tender stage for the right to provide the service (in which case they are negative), or as ex post payments made by the public authority (if positive). We will use both interpretations in what follows. Note that $\alpha_{O}$ can also be interpreted as an availability payment paid by the public authority for services where users do not pay. The incentive intensities of these contracts are captured by the parameters $\beta$ and $\gamma \cdot{ }^{14}$

Consider now the case of bundling. The conglomerate's compensation scheme writes as:

$$
t(Q, R)=\alpha+\beta Q+\gamma R .
$$

Under all circumstances below, the outside opportunity of the firm(s) gives a payoff normalized at zero. Contracts are also designed ex ante, i.e., before productivity shocks realize.

Objectives. The principal is risk-neutral and maximizes his share of revenues net of the costs of paying for the services and the infrastructure. ${ }^{15}$ Formally, under unbundling, the government's objective is

$$
R-t_{B}(Q)-t_{O}(R)-I
$$

whereas, under bundling, it becomes

$$
R-t(Q, R)-I \text {. }
$$

Those expressions presume that the principal pays by himself the investment and appropriates all revenues. Of course, it is only an accounting convention to have the builder invest $I$, and then be paid $t(Q, R)+I$.

Firm(s) are (is) risk-averse with constant degree of risk-aversion $r \geq 0$, and we denote $v(x)=1-\exp (-r x)$ this utility function. The assumption of risk-aversion captures the fact that a PPP project might represent a large share of the firm's activities so that it can hardly be viewed as being diversified. Under unbundling, the builder and the operator respectively maximize

$$
\left.E\left(v\left(t_{B}(Q)-\frac{a^{2}}{2}\right)\right) \text { and } E\left(v\left(t_{O}(R)-\frac{\mu}{2}(e-a-\theta)^{2}\right)\right)\right)
$$

\footnotetext{
${ }^{14}$ Because the first-stage investment does not directly affect revenues (only the operator's expectations on this variable does), there is no point rewarding the builder with revenues. Similarly, there is no reason to have the operator being paid according to the quality index. This is a consequence of Holmström's (1979) "Informativeness Principle". Suppose instead that the builder's effort can be observed by the operator. Then the operator chooses an effort at the operating stage that depends on the builder's realized effort at the design stage. As a result, the builder could be paid also with revenues to internalize the impact of design on subsequent stages. In practice, such payments would be difficult to implement as contracts extend to many years after the facility is built.

${ }^{15}$ This assumption of risk-neutrality may be questioned in the case of small local governments whose PPP projects may represent a significant share of their overall budget. Lewis and Sappington (1995) and Martimort and Sand-Zantman, (2007) analyze how risk-averse public authorities behave in procurement settings.
} 
where $E(\cdot)$ is the expectation operator. Under bundling, the conglomerate's objective becomes

$$
\left.E\left(v\left(t(Q, R)-\frac{a^{2}}{2}-\frac{\mu}{2}(e-a-\theta)^{2}\right)\right)\right) .
$$

Contractible efforts and shocks. When the design and operating efforts are both contractible and all shocks are perfectly insurable, efficient levels of effort maximize social welfare. Whether bundling or unbundling is chosen is clearly irrelevant and the firm(s) is (are) fully insured against all risks. Let $\left(a^{*}, e^{*}(\theta)\right)$ be those efficient levels of effort. They solve:

$$
\max _{a}\left\{-\frac{a^{2}}{2}+E_{\theta}\left(\max _{e} e-\frac{\mu}{2}(e-a-\theta)^{2}\right)+I\right\} .
$$

We find

$$
a^{*}=1 \quad \text { and } \quad e^{*}(\theta)=a^{*}+\frac{1}{\mu}+\theta .
$$

Of course, the operating effort depends on the design effort but is biased upward, and the less so as the technology is less flexible. In the limiting case where $\mu \rightarrow \infty$, the design fully determines the operating effort up to the ex post shock $\theta$. This highlights the existing positive externality between the two stages: a better design increases revenues of the service. ${ }^{16}$

Finally, only projects with positive value are undertaken, which imposes an upper bound $I^{*}$ on the feasible investments:

$$
I \leq I^{*}=\frac{1}{2}\left(1+\frac{1}{\mu}\right)
$$

Remark 1. Our framework could be modified to capture the possibility of a negative externality between design and operation. ${ }^{17}$ Suppose that the disutility of effort at the operating stage writes as

$$
\frac{\mu}{2}(e+a-\theta)^{2}
$$

The operating effort thus moves in opposite directions with the design effort. Keeping the same expression of revenues as above, there would be no benefit in investing in a good design. Alternatively, if revenues were directly an increasing function of the first-stage effort, for instance $R=\lambda a+e+\epsilon$ with $\lambda>1$, or if a good design were creating a positive externality whose social value to the principal was $S=\lambda a,{ }^{18}$ the optimal first-stage effort would remain positive. It is worth noticing that the quality index would then reflect the social value of the infrastructure. ${ }^{19}$

\section{Organizational forms under incomplete contracting}

For some public projects, uncertainty may be pervasive. The service may have been provided by the public sector in the past and at the time of delegation no data about delivery capabilities and past performances may be publicly available. ${ }^{20}$ The project may also introduce

${ }^{16}$ Once the operator knows $\theta$, his expected revenues $a+\theta$ depend on the first-stage effort and the productivity shock. Similar randomness also occurs with nonverifiable efforts. Anticipating our findings below, since the operator keeps only a share of revenues his payoff fluctuates less than $\theta$.

${ }^{17}$ An innovative design of a hospital, using recently developed materials, may lead to improved lighting and air quality, and therefore better clinical outcomes, but may also increase maintenance costs.

${ }^{18}$ An innovative design of a school using open plans may lead to a more welcoming, inclusive learning environment. An innovative design of a prison, with a gym, a workshop or an education block, can help inmates train for a job and reduce the percentage of re-offenders.

${ }^{19}$ Another interesting extension would consider the possibility that a first-stage effort affects the distribution of revenue shocks. Because of space constraints, we leave aside the study of these more complex patterns of externalities.

${ }^{20}$ Bajari and Tadelis (2001) observe that, in many procurement contexts, buyers and sellers face the same uncertainty on costs and demand beforehand. 
new services and procedures that make it difficult to foresee all contingencies that could arise during implementation..$^{21}$

To unveil the benefits of bundling tasks for such projects, let us first assume that the productivity shocks $\theta$ cannot be contracted upon ex ante. However, the realization of $\theta$ becomes common knowledge ex post. At that stage, although the operator adapts its second-stage effort to its realization, the payment is not adjusted. This captures the incompleteness of the contracting environment.

Unbundling. Consider first the builder's incentive constraint. The design effort maximizes the certainty equivalent of the builder's profit:

$$
a=\arg \max _{\tilde{a}} \alpha_{B}+\beta \tilde{a}-\frac{\tilde{a}^{2}}{2}-\frac{r \sigma^{2} \beta^{2}}{2} \equiv \beta .
$$

The builder's participation constraint written in terms of certainty equivalents becomes:

$$
U_{B}=\alpha_{B}+\left(1-r \sigma^{2}\right) \frac{\beta^{2}}{2} \geq 0 .
$$

Consider now the operator. As he knows $\theta$ and perfectly anticipates the builder's first-stage effort level, his incentive constraint writes as:

$$
e(\theta, \gamma, a)=\arg \max _{\tilde{e}} \alpha_{O}+\gamma \tilde{e}-\frac{\mu}{2}(\tilde{e}-a-\theta)^{2}-\frac{r \eta^{2} \gamma^{2}}{2} \equiv a+\theta+\frac{\gamma}{\mu} .
$$

The second-stage effort increases with the productivity shock $\theta$, and the incentive intensity $\gamma$. This expression also shows that the operator's effort responds to productivity shocks and design as in the first-best. ${ }^{22}$ However, as the operator only keeps a share of revenues, only a fraction of the productivity risk impacts on his expected payoff. Using (3), the certainty equivalent of this payoff in state $\theta$ becomes $\alpha_{O}+\gamma e(\theta, \gamma, a)-\left(\frac{1}{\mu}+r \eta^{2}\right) \frac{\gamma^{2}}{2}$. Taking into account the extra risk premium coming from uncertainty on productivity shocks, the operator's participation constraint becomes (where we make explicit the dependence on $a$ ):

$$
U_{o}(a)=\alpha_{O}+\gamma a+\left(\frac{1}{\mu}-r\left(\eta^{2}+\vartheta^{2}\right)\right) \frac{\gamma^{2}}{2} \geq 0 .
$$

Proposition 1. Suppose that $\theta$ is non-verifiable. The optimal scheme under unbundling entails the following incentive intensities and first-stage effort level:

$$
\gamma_{U}=\frac{\frac{1}{\mu}}{\frac{1}{\mu}+r\left(\eta^{2}+\vartheta^{2}\right)}<1 \quad \text { and } \quad \beta_{U}=a_{U}=\frac{1}{1+r \sigma^{2}}<1 .
$$

Those results are standard but their implications in our context are interesting. The incentive intensity $\gamma_{U}$ captures the transfer of demand risk to the operator. Transferring more demand risk (higher $\gamma$ ) raises the operator's incentives, but at the cost of a higher risk premium $\left(r\left(\eta^{2}\right.\right.$ $\left.+\vartheta^{2}\right) \gamma^{2} / 2$ ) to compensate the operator for all the risks he bears. This includes uncertainty on revenues and on the productivity shock $\theta$. When demand risk increases ( $\eta^{2}$ higher) or when operational uncertainty is higher ( $\vartheta^{2}$ higher), transferring demand risk becomes more costly (the risk premium increases) so that weaker incentives become optimal. Similar insights apply with regard to the power of the incentives scheme for the builder. As the precision of the quality index decreases $\left(\sigma^{2}\right.$ increases), incentives are reduced to decrease the risk premium $\left(r \sigma^{2} \beta^{2} / 2\right)$. A less

${ }^{21}$ This uncertainty often justifies that the public sector relies on pilot projects to experiment with a new organizational form or a new project before committing its policy to it.

${ }^{22}$ Backer and Jorgensen (2003) develop another moral-hazard model where the agent chooses his effort after some shock realizes. 
flexible technology ( $\mu$ greater) also corresponds to a lower-powered revenue-sharing agreement. It becomes harder to provide incentives at the operating stage when the corresponding effort is almost fully determined by the first-stage design.

Bundling. Consider now the case of bundling. The second-stage incentive constraint remains as in (3). Turning now to the first stage, the conglomerate anticipates the impact of design on second-stage effort and revenues. More precisely, the first-stage effort now solves

$$
\begin{aligned}
a= & \arg \max _{\tilde{a}} \alpha+\beta \tilde{a}-\frac{\tilde{a}^{2}}{2} \\
& +E_{\theta}\left(\gamma e(\theta, \gamma, \tilde{a})-\frac{\mu}{2}(e(\theta, \gamma, \tilde{a})-\tilde{a}-\theta)^{2}\right)-\frac{r\left(\eta^{2}+\vartheta^{2}\right) \gamma^{2}}{2}-\frac{r \sigma^{2} \beta^{2}}{2}
\end{aligned}
$$

where the last terms represent the risk premiums for all risks borne by the conglomerate.

Using $e(\theta, \gamma, \tilde{a})$ from (3) yields another expression of the first-stage incentive constraint as:

$$
a=\arg \max _{\tilde{a}} \alpha+(\beta+\gamma) \tilde{a}-\frac{\tilde{a}^{2}}{2}+\left(\frac{1}{\mu}-r\left(\eta^{2}+\vartheta^{2}\right)\right) \frac{\gamma^{2}}{2}-\frac{r \sigma^{2} \beta^{2}}{2} \equiv \beta+\gamma .
$$

Now incentive intensities at both stages contribute to raising the first-stage effort.

The conglomerate's participation constraint written in terms of certainty equivalents is:

$$
U(a)=\alpha+(\beta+\gamma) a-\frac{a^{2}}{2}+\left(\frac{1}{\mu}-r\left(\eta^{2}+\vartheta^{2}\right)\right) \frac{\gamma^{2}}{2}-\frac{r \sigma^{2} \beta^{2}}{2} \geq 0 .
$$

Proposition 2. Suppose that $\theta$ is non-verifiable. The optimal scheme under bundling entails the following properties.

- Incentive intensities on profits (resp. quality) are greater (resp. lower) than under unbundling:

$$
\begin{gathered}
1>\gamma_{B}=\frac{\frac{1}{\mu}+\frac{r \sigma^{2}}{1+r \sigma^{2}}}{\frac{1}{\mu}+\frac{r \sigma^{2}}{1+r \sigma^{2}}+r\left(\eta^{2}+\vartheta^{2}\right)}>\gamma_{U}, \\
1>\beta_{U}>\beta_{B}=\frac{1}{1+r \sigma^{2}} \frac{r\left(\eta^{2}+\vartheta^{2}\right)}{\frac{1}{\mu}+\frac{r \sigma^{2}}{1+r \sigma^{2}}+r\left(\eta^{2}+\vartheta^{2}\right)} .
\end{gathered}
$$

- The first-stage effort $a_{B}$ is greater than under unbundling but still lower than the first-best:

$$
a_{B}=\frac{1+\gamma_{B} r \sigma^{2}}{1+r \sigma^{2}} \in\left(a_{U}, 1\right) .
$$

Under bundling, the principal can rely on both $\beta$ and $\gamma$ to provide incentives for first-stage effort. The first instrument is direct, whereas the second is indirect. A revenue-sharing scheme indeed rewards the merged entity for his operational effort, which is indirectly positively linked to the first-stage effort. Because of this positive externality, agency costs exhibit economies of scope. The power of incentives is greater under bundling and the agent keeps a larger share of revenues. At the same time, relying on a quality index becomes less attractive, which highlights a substitutability between direct and indirect rewards for first-stage effort. Keeping a greater share of revenues in turn boosts the design effort because the firm takes now into account the impact of a better design on operational costs. With lower operational costs, the second-stage effort increases which raises revenues. From the definition of operational efforts under both organizational forms, we indeed obtain:

$$
e\left(\theta, \gamma_{B}, a_{B}\right)>e\left(\theta, \gamma_{U}, a_{U}\right) \quad \forall \theta
$$


Importantly, the incentive intensities $\beta$ and $\gamma$ move in opposite directions. A more noisy quality index means that this index is less useful to provide first-stage incentives. But as a substitute, the firm should keep more of its revenues. On the contrary, when revenues are more risky, there is less value in using revenues to provide first-stage incentives. By the same token, as the technology becomes more flexible ( $\mu$ decreases), $\gamma_{B}$ increases whereas $\beta_{B}$ decreases. The principal relies more on revenues sharing because the conglomerate's operational effort becomes more responsive to second-stage incentives. ${ }^{23}$

Welfare comparison. The comparison between organizational forms is now straightforward.

Proposition 3. Bundling is always the optimal organizational form.

Related results have been found in the existing agency literature although in slightly different contexts (see our review of the literature). Our novel finding is that this welfare comparison takes now into account uncertainty in the mapping between first-stage and second-stage effort at the time of making the choice on the optimal organizational form. Nevertheless, the strong positive relationship between investment and operational efforts justifies an unambiguous choice of bundling. This suggests a potential gain from PPPs during a first stage of delegation to the private sector, where uncertainty is pervasive and insufficient past evidence is available to inform parties of what may arise later at the operational stage.

Bundling has the greatest benefits when $\sigma^{2}=+\infty$, i.e., with no useful quality index. Indeed, with separate entities, there is no way to incentivize the builder. Instead, the conglomerate takes into account the impact of design on revenues and exerts a positive first-stage effort. Similarly, when $\mu$ goes to zero and the technology is very flexible, the positive externality across stages is large. The revenue-sharing scheme is high-powered ( $\gamma$ close to one), and again bundling has the greatest benefits.

The gains from bundling are also high when demand risk is low, service standards can be measured precisely ( $\eta^{2}$ is low), or when operational risk is low ( $\vartheta^{2}$ is low) so that the firm keeps most revenues and better internalizes externality across stages ( $\gamma$ is high). To illustrate, PPPs may be beneficial for standard transport projects, such as toll roads and motorways, where traffic information is well documented. Social houses and public accommodations also show low demand risk although there reliable infrastructure quality indexes might also be available. Traditional procurement with unbundling may instead be preferable for new toll road projects in less developed areas, or for innovative transport projects, where both demand and operational risks are high. ${ }^{24}$

Finally, bundling facilitates initial investment into the project. Indeed, the condition for a positive net present value project under bundling becomes

$$
I \leq I_{B}=\frac{1}{2\left(1+r \sigma^{2}\right)}+\frac{\left(\frac{1}{\mu}+\frac{r \sigma^{2}}{1+r \sigma^{2}}\right)^{2}}{2\left(\frac{1}{\mu}+\frac{r \sigma^{2}}{1+r \sigma^{2}}+r\left(\eta^{2}+\vartheta^{2}\right)\right)}<I^{*} .
$$

Instead, under unbundling the condition is more stringent:

$$
I \leq I_{U}=\frac{1}{2\left(1+r \sigma^{2}\right)}+\frac{1}{2 \mu^{2}\left(\frac{1}{\mu}+r\left(\eta^{2}+\vartheta^{2}\right)\right)}<I_{B} .
$$

\footnotetext{
${ }^{23}$ When $\mu \rightarrow+\infty$, revenues become just a noisy measure of first-stage effort, namely $R=a+\theta+\zeta$, which should be used to also reward the firm for its first-stage effort. However, revenues do not provide any incentives for the operational effort which is fully determined by the design stage.

${ }^{24}$ For example, high uncertainty in demand forecast characterized the highly innovative Channel Tunnel Rail Link connecting England to France (see NAO, 2007).
} 
That comparison explains the pervasive use of PPP contracts in European countries at the time governments' budget constraints are tight. In the United Kingdom, for example, PPPs were highly promoted by the Labour Party public authority on efficiency grounds, though critics also suggested that behind its political support lied also the desire to promote private infrastructure investment even though the limits imposed by the Maastricht Treaty are tight (IPPR, 2001). Following Engel, Fischer, and Galetovic (forthcoming), we know that there is no justification for PPPs from freeing public funds per se. Our analysis unveils that PPPs may nevertheless relax budget constraints and facilitate investment based solely on efficiency grounds.

\section{The mature phase of delegation: verifiable productivity shocks}

So far we have modeled uncertain environments where productivity shocks cannot be described ex ante and remain noncontractible. That setting, as we mentioned, was suitable to capture the initial phase of delegation of public service provision to the private sector, where little past experience exists to assess operational risks. Only incomplete contracts that are not contingent on the productivity shocks were feasible. We now consider less uncertain environments where productivity shocks can be foreseen ex ante and thus described in a more complete contract. Ex post, contracting partners will have common knowledge of those shocks. Such a setting can be thought of as representing a more mature phase of delegation, where some past experience exists to inform parties as to what might or might not happen as events unfold. ${ }^{25}$

Information structure. We assume from now on that $\theta$ has still zero mean but can only take two values $\bar{\theta}=(1-v) \Delta \theta>0$ and $\underline{\theta}=-v \Delta \theta<0$ with respective probabilities $v$ and $1-$ $\nu$. We denote $\Theta=\{\underline{\theta}, \bar{\theta}\}$. Let also $E_{\theta}(\cdot) \bar{b}$ e the expectation operator with respect to $\theta .{ }^{26}$ Notice that the first-best operational effort in the good state $\bar{\theta}$ is greater than in the bad state $\underline{\theta}^{27}$

Unbundling. Consider first the case where the operator and builder are kept as separated entities. Only the operator suffers from the productivity risk and must be somewhat insured against it. At the same time, the builder is still rewarded as a function of the realized quality index and operates under a linear scheme $t_{B}(Q)=\alpha_{B}+\beta Q$. This contract is independent of the productivity shock because this shock has not yet realized at the time the builder is paid.

Let us now turn to the description of the operator's contract. The largest class of contracts that can be written ex ante stipulates a menu of revenues sharing schemes that depend on the realized shock parameter $\theta$ because that shock is ex post common knowledge and contractible. Such a menu is designed with the dual objective of providing insurance to the operator against productivity shocks but also of inducing operational effort. Such a mechanism is a collection $\left\{\left(\alpha_{O}(\theta), \gamma(\theta)\right)\right\}_{\theta \in \Theta}$.

Abusing slightly our previous notations, we define the certainty equivalent of the operator's payoff in state $\theta$ as

$$
U_{O}(\theta, a)=\max _{\tilde{e}} \alpha_{O}(\theta)+\gamma(\theta) \tilde{e}-\frac{\mu}{2}(\tilde{e}-a-\theta)^{2}-\frac{r \eta^{2} \gamma^{2}(\theta)}{2} .
$$

This expression makes it clear that the risk borne in fine by the operator depends on the revenuesharing agreement. Unless the principal chooses to always leave all revenues to the firm (i.e., $\gamma(\theta) \equiv 1$, which is very bad from an insurance point of view), the fluctuations of the operator's payoff only partially reflect those of the productivity shock.

\footnotetext{
${ }^{25}$ When $\theta$ is verifiable, one could a priori think that this shock can be insured. This would be the case had revenues written as $R=e+\theta+\epsilon$ with contracts depending on the verifiable variable $\tilde{R}=R-\theta=e+\epsilon$. Here instead, $\theta$ affects the operator's nonverifiable cost and only impacts indirectly on revenues. Partial insurance is nevertheless still possible.

${ }^{26}$ The variance of $\theta$ is $\vartheta^{2}=v(1-v)(\Delta \theta)^{2}$. With this expression at hand, it can be checked that, with CARA preferences, the formula for the incentive intensities already derived for normal distributions are also valid when $\Delta \theta$ is small enough even if $\theta$ follows such a discrete distribution.

${ }^{27}$ This monotonicity property will carry over to the case where $\theta$ is private information.
} 
Using the definition of the optimal operational effort given from (3), we finally obtain

$$
U_{O}(\theta, a)=\alpha_{O}(\theta)+\gamma(\theta)(a+\theta)+\left(\frac{1}{\mu}-r \eta^{2}\right) \frac{\gamma^{2}(\theta)}{2} .
$$

Because $\theta$ is still unknown at the time of contracting, the risk-averse operator's participation constraint becomes:

$$
E_{\theta}\left(v\left(U_{O}(\theta, a)\right)\right) \geq 0 . .^{28}
$$

Optimal incentive schemes. We can characterize the optimal contract as follows.

Proposition 4. Suppose that $\theta$ is common knowledge ex post and verifiable. The optimal scheme under unbundling entails the following properties.

- The operator is fully insured against productivity shocks, the fixed payment being lower in state $\bar{\theta}$ :

$$
U_{O}\left(\bar{\theta}, a_{B}^{*}\right)=U_{O}\left(\underline{\theta}, a_{B}^{*}\right)=0 \text { and } \alpha_{O}^{*}(\underline{\theta})>\alpha_{O}^{*}(\bar{\theta}) .
$$

- The builder operates under the same scheme as when $\theta$ is nonverifiable and exerts the same first-stage effort:

$$
\beta_{U}^{*}=\beta_{U} \text { and } a_{U}^{*}=a_{U} .
$$

- The share of revenues kept by the operator does not depend on the productivity shock but is greater than when productivity shocks are nonverifiable, and operational effort is higher:

$$
\gamma_{U}^{*}(\bar{\theta})=\gamma_{U}^{*}(\underline{\theta})=\gamma_{U}^{*}>\gamma_{U} \text { and } e\left(\theta, \gamma_{U}^{*}, a_{U}^{*}\right)>e\left(\theta, \gamma_{U}, a_{U}\right) \quad \forall \theta \in \Theta .
$$

Contracts between the public and private sectors for the provision of a service often entail fixed payments to reflect external conditions affecting the operator's profits (HM Treasury, 2007). When a negative shock realizes during operations (for example, input prices increase, or a national strike slows down production or there is a change in legislation that increases the cost of operations), the firm receives a compensation from the authority. When instead a positive shock hits (for example, lending conditions improve so that the firm can refinance its debt, reducing its cost of capital), the firm shares the benefit with the authority. This also holds in our context, where the fixed payment fully compensates the operator for the lost revenues:

$$
0<\alpha_{O}^{*}(\underline{\theta})-\alpha_{O}^{*}(\bar{\theta})=\gamma_{U}^{*} \Delta \theta<\Delta \theta .
$$

As the shocks are exogenous and thus outside the firm's control, providing for these "compensation events" does not weaken incentives to exert effort. In fact, by reducing the noise-to-signal ratio, this insurance reduces the risk premium and thus the cost of incentives. ${ }^{29}$ Incentives for operating effort are thus boosted by letting the firm keep more revenues.

An important aspect of the analysis is that the share of revenues kept by the operator does not depend on the productivity shock. There is a dichotomy between solving moral hazard which is done with an incentive intensity independent of the productivity shock and providing insurance which is obtained by modifying the fixed payment. The reasoning is familiar from agency theory. Making the incentive intensity $\gamma$ depend on $\theta$ would add further noise to the firm's overall

${ }^{28}$ The firm may run a loss for a bad realization of $\theta$ as long as it breaks even in expectations. As seen below, when $\theta$ is verifiable, full insurance is possible and this ex ante participation constraint is replaced by ex post participation constraints which ensure that the firm makes zero expected profit for each $\theta$.

${ }^{29}$ To see why, suppose again that $\theta$ is nonverifiable and revenue-sharing schemes are independent of $\theta$. Supposing that $\Delta \theta$ is small enough, the extra risk premium $r \vartheta^{2} \beta^{2} / 2$ where $\vartheta^{2}=v(1-v)(\Delta \theta)^{2}$ must be paid to ensure the operator's participation, which leads to the same analysis as in Section 3 . 
compensation without inducing cheaper incentives because the operator's effort does not affect the distribution of $\theta .^{30}$

Bundling. Again the conglomerate can be induced to exert first-stage effort by rewarding its performances according to the quality index, but now a revenue-sharing agreement can also be contingent on the productivity shock to provide better insurance. To keep symmetry with the unbundling case, we assume that rewards on quality index are made just after the design stage and cannot be contingent on the future productivity shock. A mechanism is thus now a collection $\{(\alpha(\theta), \gamma(\theta))\}_{\theta \in \Theta}$ with a fixed incentive reward on quality $\beta .{ }^{31}$ Overall, the conglomerate operates under a linear scheme that a priori depends on the realization of $\theta$ and writes as:

$$
t(Q, R, \theta)=\alpha(\theta)+\beta Q+\gamma(\theta) R .
$$

The second-stage incentive constraint is kept unchanged and remains as in (3). To study the firm's first-stage incentive constraint, it is useful to rewrite its overall expected payoff as

$$
E_{\theta}\left(v\left(\beta a-\frac{a^{2}}{2}-\frac{r \sigma^{2} \beta^{2}}{2}+U_{O}(\theta, a)\right)\right) .
$$

For each realization of $\theta$, the conglomerate's profit is the sum of its payoffs as a builder and as an operator. In particular, the profit from operating assets $U_{O}(\theta, a)$ is still defined as in (12). This expression makes it also clear how the conglomerate anticipates the impact of design on second-stage revenues. More precisely, the first-stage effort now solves:

$$
a=\arg \max _{\tilde{a}} E_{\theta}\left(v\left(\beta \tilde{a}-\frac{\tilde{a}^{2}}{2}-\frac{r \sigma^{2} \beta^{2}}{2}+U_{O}(\theta, \tilde{a})\right)\right) .
$$

On the other hand, inducing the conglomerate's participation requires now that

$$
E_{\theta}\left(v\left(\beta a-\frac{a^{2}}{2}-\frac{r \sigma^{2} \beta^{2}}{2}+U_{o}(\theta, a)\right)\right) \geq 0 .
$$

Proposition 5. Suppose that $\theta$ is common knowledge ex post and verifiable. The optimal scheme under bundling entails the following properties:

(i) The firm is fully insured against productivity shocks. Fixed payments are lower in state $\bar{\theta}$ :

$$
\beta_{B}^{*} a_{B}^{*}-\frac{\left(a_{B}^{*}\right)^{2}}{2}-\frac{r \sigma^{2}\left(\beta_{B}^{*}\right)^{2}}{2}+U_{O}\left(\theta, a_{B}^{*}\right)=0 \quad \forall \theta \quad \text { and } \quad \alpha_{B}^{*}(\bar{\theta})<\alpha_{B}^{*}(\underline{\theta}) .
$$

(ii) The share of revenues kept by the firm does not depend on the productivity shock but is greater than when productivity shocks are nonverifiable:

$$
\gamma_{B}^{*}(\theta)=\gamma_{B}^{*}>\gamma_{B} \quad \forall \theta \in \Theta .
$$

(iii) Infrastructure quality is less rewarded than when productivity shocks are nonverifiable:

$$
\beta_{B}^{*}<\beta_{B} .
$$

(iv) Efforts are greater than when productivity shocks are nonverifiable:

$$
a_{B}^{*}>a_{B} \quad \text { and } \quad e_{B}^{*}\left(\theta, \gamma_{B}^{*}, a_{B}^{*}\right)>e_{B}\left(\theta, \gamma_{B}, a_{B}^{*}\right) \quad \forall \theta \in \Theta .
$$

As under unbundling, ensuring the firm against productivity shocks reduces the risk premium and makes it more attractive to rely on revenues to boost first-stage effort. Now, however, relying

\footnotetext{
${ }^{30}$ The proof of this result is more involved than what intuition suggests. Indeed, the operational effort is chosen after productivity shocks realize and the principal might want to transfer wealth across different states to reduce agency costs. The absence of income effect ensures it is suboptimal.

${ }^{31}$ Without loss of generality, we incorporate the fixed payment $\alpha_{B}$ into $\alpha(\theta)$. 
on the quality index is also less attractive. The quality index provides incentives at the design stage, but under bundling, revenue-sharing also provides such incentives, albeit indirectly. When $\theta$ is common knowledge, improving the noise-to-signal ratio at the operating stage raises the effectiveness of revenue-sharing, compared to the quality index, as an instrument to provide incentives on design. Overall, operational efforts is boosted directly, as more of the revenues are kept by the firm than when productivity shocks are nonverifiable, and indirectly, as first-stage effort is greater.

These results suggest that the firm's compensation relies more on the revenues from the service (or on service standards in cases where users do not pay) when the risks that the contractor cannot control can be well identified ex ante (so as to be accounted for in the contract) and ex post (so that compensations can be paid) and then taken by the public sector.

Welfare comparison. The comparison between organizational forms is straightforward. The fact that the risk borne by the firm(s) with complete contracts is reduced does not change the dominant organizational form. But with risk at the operating stage being shared more efficiently (in the sense that the noise-to-signal ratio decreases), revenue-sharing becomes a more effective instrument to provide incentives, and the relative gain of bundling increases. ${ }^{32}$

Proposition 6. Suppose that $\theta$ is common knowledge ex post and verifiable. Bundling is again the optimal organizational form. Compared to the case where $\theta$ is nonverifiable, the gains of bundling tasks are greater.

When the firm can use its past experience to predict events that may realize during operations, and when the authority also has such experience, they can agree that the firm will not be responsible for events beyond its control. Risk identification and risk allocation in PPP contracts is indeed key. Standardized PPP contracts typically contain a "risk matrix" that spells out, for each event that can be predicted, how the risk should be allocated between the private and the public sector. Risk-sharing considerations in best international practices are in line with our suggestions. ${ }^{33}$ Our analysis shows that the benefits of bundling are the greatest. PPPs become particularly effective at incentivizing innovative approaches to public service provision ( $a$ increases) and containing the cost of operations ( $e$ increases). It is reasonable to assume that the shocks $\theta$ become observable and verifiable as experience accumulates in the sector. Hence, our analysis suggests that the benefits from PPPs, although positive also under incomplete contracting, will increase as delegation gets more mature.

Finally, it is interesting to observe that even more projects can now be financed under bundling. The condition for a positive net present value becomes:

$$
I \leq I_{B}^{*}=\frac{1}{2\left(1+r \sigma^{2}\right)}+\frac{\left(\frac{1}{\mu}+\frac{r \sigma^{2}}{1+r \sigma^{2}}\right)^{2}}{2\left(\frac{1}{\mu}+\frac{r \sigma^{2}}{1+r \sigma^{2}}+r \eta^{2}\right)}, \quad \text { where } \quad I_{B}^{*}>I_{B} .
$$

\section{The cost of innovation: asymmetric information on productivity shocks}

- The complexity of operations undertaken by a contractor may vary greatly from one sector to the other and even within the same sector. Complexity is low when the contractor is responsible for simple, low-skilled repetitive tasks that are not critical to the service operation, or for facilities

\footnotetext{
${ }^{32}$ When the quality index cannot be used to contract, the builder has no incentives under unbundling and only bundling can induce some first-stage effort. With more complete contracts, leaving more revenues to the conglomerate firm boosts its first-stage effort.

${ }^{33}$ Risk matrixes may contain hundreds of different entries, one for each identifiable risk. 
management services considered routine for buildings and basic civil infrastructure. Complexity is higher for technically demanding services that require specific project management skills, such as operating complex medical or process engineering equipment. Complex projects are also those for which a new design and services might be introduced, existing procedures and approaches might be changed, and new technologies may be experienced. The degree of complexity in a project is important because it affects project risk. ${ }^{34}$

With complex projects, the specialized skills required to manage the service and the changes introduced by the innovations typically make past information within the public sector of little use to assess current risks. The greater uncertainty at operational stage that this complexity brings about is then combined with an informational advantage of the operator on the productivity shocks that affect operations. In this section, we analyze the role of PPPs in such scenarios, where complexity, risk, and asymmetric information come together.

With asymmetric information, the contract that was offered to the operator when $\theta$ was common knowledge is no longer feasible. Whether bundling or unbundling has been chosen, an operator having faced a high productivity shock wants to report a low one in order to receive a higher payment $(\alpha(\bar{\theta})<\alpha(\underline{\theta}))$. There is now a tension between truth telling and insurance.

Whether bundling or unbundling is chosen, screening mechanisms must be used to induce the operator to reveal information on the realized productivity shock that he has privately observed. A menu of screening mechanisms stipulates revenue-sharing agreements that depend now on the operator's announcement $\hat{\theta}$ on the realization of the shock parameter $\theta$. By the Revelation Principle (Myerson, 1982), there is no loss of generality in considering schemes of the form $\left\{\left(\alpha_{O}(\theta), \gamma(\theta)\right)\right\}_{\theta \in \Theta}$ that induce truthful revelation. Such a menu is now designed with the triple goals of providing the builder with insurance against productivity shocks, inducing efforts at both stages, and inducing truth telling on productivity shocks.

Unbundling. Consider first the operator's incentive problem. Let the operator's ex post information rent (i.e., once informed on $\theta$ ) now be defined as

$$
\begin{aligned}
U_{O}(\theta, a) & =\max _{(\tilde{e}, \hat{\theta})} \alpha_{O}(\hat{\theta})+\gamma(\hat{\theta}) \tilde{e}-\frac{\mu}{2}(\tilde{e}-a-\theta)^{2}-\frac{r \eta^{2} \gamma^{2}(\hat{\theta})}{2} \\
& =\max _{\hat{\theta}} \alpha_{O}(\hat{\theta})+\gamma(\hat{\theta})(a+\theta)+\left(\frac{1}{\mu}-r \eta^{2}\right) \frac{\gamma^{2}(\hat{\theta})}{2}
\end{aligned}
$$

where $a$ is the equilibrium first-stage effort that is anticipated by the operator. This expression encompasses the usual incentive compatibility constraints that are both necessary and sufficient to induce truthful revelation once $\theta$ is known. In particular, the incentive compatibility constraint that prevents an operator hit by a positive shock $\bar{\theta}$ to pretend having faced a more averse shock $\underline{\theta}$ can be expressed as:

$$
U_{O}(\bar{\theta}, a)-U_{O}(\underline{\theta}, a) \geq \Delta \theta \gamma(\underline{\theta}) .
$$

Of course, this constraint is the only relevant one (binding) in our framework with two productivity shocks (see, e.g., Laffont and Martimort, 2002, Chapter 2). By under-reporting his productivity, the operator claims lower revenues and receives a greater fixed payment. With such strategy, the high-productivity firm appropriates an extra rent worth $\Delta \theta \gamma(\underline{\theta})$. This rent is strictly positive unless $\gamma(\underline{\theta})=0$. Setting $\gamma(\underline{\theta}) \equiv 0$ would of course remove incentives to lie but it would also destroy all incentives to exert effort to boost revenues following a negative shock.

Proposition 7. Suppose that the operator has private information on $\theta$. The optimal scheme under unbundling entails the following properties:

${ }^{34}$ Moody's (2007) identifies different categories of project complexity and assigns a higher degree of risk to more complex projects. 
(i) The firm is only partially insured against productivity shocks:

$$
\hat{U}_{O}\left(\bar{\theta}, \hat{a}_{U}\right)>0>\hat{U}_{O}\left(\underline{\theta}, \hat{a}_{U}\right) \text {. }
$$

(ii) The share of revenues kept by the operator is greater and the operating effort is higher when a good productivity shock hits:

$$
\hat{\gamma}_{U}(\bar{\theta})=\gamma_{U}^{*}>\hat{\gamma}_{U}(\underline{\theta})>0 \quad \text { and } \quad \hat{e}_{U}(\bar{\theta})=e_{U}^{*}>\hat{e}_{U}(\underline{\theta}) .
$$

(iii) Incentive intensities on quality and first-stage effort are the same as when productivity shocks are verifiable:

$$
\hat{\beta}_{U}=\beta_{U}^{*} \quad \text { and } \quad \hat{a}_{U}=a_{U}^{*} .
$$

The important insight of Proposition 7 is that solving the asymmetric information problem imposes an endogenous risk on the operator (now $\hat{U}_{O}\left(\bar{\theta}, \hat{a}_{U}\right)>\hat{U}_{O}\left(\underline{\theta}, \hat{a}_{U}\right)$ ). This calls for less powerful incentives at the operating stage when a bad shock hits.

On top, the optimal contract exhibits three important features. First, a revenue-sharing rule dependent on the productivity shock is necessary to ensure truth telling. If $\gamma$ were kept independent of $\theta$ (as when shocks are verifiable), the firm would always report a negative shock and retain the unreported revenues.

Second, the firm is now exposed to productivity risk beyond its control because it facilitates truth telling. The fixed compensation following a bad shock is reduced.

Third, the truth telling incentive constraint is also relaxed by reducing the share of revenues kept by the operator in state $\underline{\theta}$ although it comes at the cost of reducing its incentives to exert effort. (In the Appendix, we show that, in the limit when $\Delta \theta$ is itself large, $\gamma_{U}(\underline{\theta})$ converges toward zero.) Instead, following a good shock $\bar{\theta}$, as much of revenue risk is transferred to the public authority as when productivity shocks are contractible. Incentives to boost revenues at the operating stage are preserved. Because he is not concerned with productivity risk, the builder receives the same compensation scheme as when productivity shocks are verifiable. Of course, this property will no longer hold with bundling.

Bundling. A mechanism is still a collection $\{(\alpha(\theta), \gamma(\theta))\}_{\theta \in \Theta}$ with a fixed incentive reward on quality $\beta$. Of course, such scheme has now to be incentive-compatible. Slightly abusing our previous notations, we again define the firm's certainty equivalent payoff from operating assets in state $\theta$ as:

$$
\begin{aligned}
U_{O}(\theta, a) & =\max _{(\tilde{e}, \hat{\theta})} \alpha(\hat{\theta})+\gamma(\hat{\theta}) \tilde{e}-\frac{\mu}{2}(\tilde{e}-a-\theta)^{2}-\frac{r \eta^{2} \gamma^{2}(\hat{\theta})}{2} \\
& =\max _{\hat{\theta}} \alpha(\hat{\theta})+\gamma(\hat{\theta})(a+\theta)+\left(\frac{1}{\mu}-r \eta^{2}\right) \frac{\gamma^{2}(\hat{\theta})}{2} .
\end{aligned}
$$

Standard arguments show that truth telling constraints imply the monotonicity condition $\gamma(\bar{\theta}) \geq$ $\gamma(\underline{\theta})$. To induce revelation, more risk should be passed to the firm following a good productivity shock. Greater effort to boost revenues follows in this state.

The analysis of the firm's first-stage incentive constraint now requires some care. Even though the menu $\{(\alpha(\theta), \gamma(\theta))\}_{\theta \in \Theta}$ can be designed to induce truthful revelation given that the firm exerts the equilibrium level of effort $a$, truthful revelation is no longer guaranteed when the firm deviates to another effort $\tilde{a}$. To see that more clearly, suppose that, as in the case of unbundling, the principal wants to implement an effort level $a$ that just leaves the firm indifferent between lying or not on the productivity shock, namely (16) is binding:

$$
\begin{aligned}
U_{o}(\bar{\theta}, a) & =\alpha(\bar{\theta})+\gamma(\bar{\theta})(a+\bar{\theta})+\left(\frac{1}{\mu}-r \eta^{2}\right) \frac{\gamma^{2}(\bar{\theta})}{2}=\alpha(\underline{\theta})+\gamma(\underline{\theta})(a+\bar{\theta})+\left(\frac{1}{\mu}-r \eta^{2}\right) \frac{\gamma^{2}(\underline{\theta})}{2} \\
& =U_{O}(\underline{\theta}, a)+\Delta \theta \gamma(\underline{\theta}) .
\end{aligned}
$$


Such a contract imposes thus the minimal amount of risk on the firm that is necessary to induce truth telling once $\theta$ gets known. Suppose on top that the allocation is separating and such that $\gamma(\bar{\theta})>\gamma(\underline{\theta})$. If the firm deviates toward a greater level of effort than that conjectured in equilibrium, $\tilde{a}>a$, truth telling is preserved. Indeed, we have

$$
\begin{aligned}
U_{O}(\bar{\theta}, \tilde{a}) & =\alpha(\bar{\theta})+\gamma(\bar{\theta})(\tilde{a}+\bar{\theta})+\left(\frac{1}{\mu}-r \eta^{2}\right) \frac{\gamma^{2}(\bar{\theta})}{2}=U_{O}(\bar{\theta}, a)+\gamma(\bar{\theta})(\tilde{a}-a) \\
& >U_{O}(\underline{\theta}, a)+\Delta \theta \gamma(\underline{\theta})+\gamma(\underline{\theta})(\tilde{a}-a)=\alpha(\underline{\theta})+\gamma(\underline{\theta})(\tilde{a}+\bar{\theta})+\left(\frac{1}{\mu}-r \eta^{2}\right) \frac{\gamma^{2}(\underline{\theta})}{2} .
\end{aligned}
$$

Instead, if the firm deviates toward a lower level of effort $\tilde{a}<a$, that last inequality would be reversed so that, in state $\bar{\theta}$, the firm would prefer to pretend having been hit by a bad shock. Intuitively, with asymmetric information, the principal would like the conglomerate to bear more risk following a good shock so that truth telling is induced. However, the firm can reduce its risk exposure by simultaneously reducing its first-stage effort and later on claiming to be hit by a negative productivity shock. Preventing such "double deviation" is now an issue that was absent under unbundling. It requires to make it more attractive for the firm to claim being hit by a good productivity shock by increasing the corresponding payoff which in turns increases the amount of risk passed onto the firm.

To solve the agency problem in that context, we first describe the form that the truth telling incentive constraint must take to also control for this double deviation.

Proposition 8. Suppose that the principal wants to implement an effort $a$. The following two conditions are necessary to induce truth telling ex post and no deviation (either downward or locally upward ${ }^{35}$ ) away from the first-stage effort $a$ at minimal agency cost.

1. The truth-telling constraint must write as

$$
U_{O}(\bar{\theta}, a)-U_{O}(\underline{\theta}, a)=\Delta \theta \gamma(\underline{\theta})+\xi(\gamma(\underline{\theta}), \Delta \gamma),
$$

where $\Delta \gamma=\gamma(\bar{\theta})-\gamma(\underline{\theta}) \geq 0$ and $\xi(\gamma(\bar{\theta}), \Delta \gamma)$ is such that $\xi(\gamma(\bar{\theta}), 0)=0$ and $\xi(\gamma(\bar{\theta}), \Delta \gamma)>$ 0 for $\Delta \gamma>0$.

2. The first-stage effort must satisfy

$$
a=\beta+\gamma(\underline{\theta})+\frac{v \Delta \gamma}{v+(1-v) \exp (r(\Delta \theta \gamma(\underline{\theta})+\xi(\gamma(\underline{\theta}), \Delta \gamma)))} .
$$

The new generalized incentive constraint (17) encompasses both the possibility of ex ante moral hazard and ex post adverse selection deviations in a rather tractable way. To screen the firm according to its productivity shock, the principal must implement revenue-sharing schemes that are separating and satisfy $\Delta \gamma>0$. But preventing the firm's "double deviation" requires letting the firm bear extra risk to ensure that the truth telling constraint is actually slack. The term $\xi(\gamma(\bar{\theta}), \Delta \gamma)$ represents how much extra slack is needed; it captures the new agency cost coming from asymmetric information. Because of the extra risk borne at the operational stage, providing incentives on design is more costly than when $\theta$ is verifiable as captured by the incentive constraint (18) which now generalizes (6). ${ }^{36}$

\footnotetext{
${ }^{35}$ Conditions (17) and (18) are only necessary and not sufficient because they are obtained by considering either downward deviations or local upward deviations away from the level of effort $a$ that one wants to implement. In particular, upward deviations are never so large that it could become attractive to have countervailing incentives, with the firm claiming to be in state $\bar{\theta}$ when instead $\underline{\theta}$ realized. In other words, some of the first-stage effort levels and rent profiles satisfying (17) and (18) may no longer be feasible when such large deviations are considered. The argument developed below is that the optimal effort within the (possibly) larger set of implementable allocations that we so describe might indeed be achieved with a contract — which, anticipating the findings in Proposition 9, is pooling — that is actually immune to such nonlocal upward deviations.

${ }^{36}$ When the firm becomes more risk-averse ( $r$ increases), the revenue-sharing agreement in the worst state $\underline{\theta}$ matters more when choosing the first-period effort. Incentives to under supply that first-period effort are exacerbated.
} 
Our analysis demonstrates that the compounding of first-stage moral hazard and ex post asymmetric information makes it costly to offer different revenue-sharing schemes for different realizations of $\theta$. Although such screening is attractive to solve the asymmetric information side of the problem and provide insurance, it weakens incentives for efforts. Our next result unveils a condition under which this trade-off tilts the optimal mechanism under bundling toward pooling, i.e., $\Delta \gamma=0$.

Proposition 9. Suppose that the firm has private information on $\theta$ and that $\Delta \theta$ is small enough. Then, the optimal pooling mechanism is such that

$$
\hat{\gamma}_{B}(\bar{\theta})=\hat{\gamma}_{B}(\underline{\theta})=\hat{\gamma}_{B} \in\left(\hat{\gamma}_{U}, \gamma_{B}^{*}\right) .
$$

This pooling mechanism implements an effort $\hat{a}_{B}$ such that

$$
\hat{a}_{B}<a_{B}^{*} .
$$

This mechanism cannot be improved upon by offering separating allocations and slightly increasing $\hat{\gamma}_{B}(\bar{\theta})$ above $\hat{\gamma}_{B}(\underline{\theta})$. $^{37}$

When uncertainty on productivity shocks is small, screening the firm with different contracts does not help much but it requires a costly slack on the truth telling constraint. The principal prefers to pool over revenue-sharing schemes to limit the first-stage effort distortion even though this destroys insurance against productivity shocks.

Renegotiation. Suppose instead that the optimal mechanism under bundling is separating, i.e., $\Delta \gamma>0 .{ }^{38}$ Such a separating mechanism is not immune to the possibility of an interim renegotiation which would take place just after the design stage but still before the firm learns the productivity shock and chooses accordingly its operational effort. As the first-stage effort is now sunk under such a scenario, a renegotiation toward a contract with incentive intensities $\gamma^{R}(\theta)$, fees $\alpha^{R}(\theta)$, and payoffs $U_{O}^{R}(\theta, a)$ would reduce the risk borne at the operating stage to its minimal amount consistent with truthful revelation of the productivity shock $\theta$. There is no longer any reason to leave a slack on the truth-telling constraint which now becomes

$$
U_{O}^{R}(\bar{\theta}, a)-U_{O}^{R}(\underline{\theta}, a)=\Delta \theta \gamma^{R}(\underline{\theta}) .
$$

Of course, anticipating that such renegotiation may provide more insurance against productivity shocks, ${ }^{39}$ the firm finds it attractive to reduce its first-stage effort, as we have seen above. The "double deviation" kicks in.

Insisting on (deterministic) contracts that remain renegotiation-proof thus forces the principal to offer pooling allocations which are immune to such renegotiation:

$$
\gamma^{R}(\bar{\theta})=\gamma^{R}(\underline{\theta}) \quad \text { and } \quad \alpha^{R}(\bar{\theta})=\alpha^{R}(\underline{\theta}) .
$$

Mutatis mutandis, Proposition 9 applies again for those renegotiation-proof contracts for any $\Delta \theta$. We can state:

Proposition 10. Suppose that the firm has private information on $\theta$ and that renegotiation-proof contracts are offered. Then, the optimal renegotiation-proof mechanism under bundling is such that the revenue-sharing agreement is independent of the productivity shocks:

$$
\hat{\gamma}_{B}(\bar{\theta})=\hat{\gamma}_{B}(\underline{\theta})=\hat{\gamma}_{B} \in\left(\hat{\gamma}_{U}, \gamma_{B}^{*}\right) \text {. }
$$

This pooling mechanism implements an effort $\hat{a}_{B}$ such that

$$
\hat{a}_{B}<a_{B}^{*} .
$$

\footnotetext{
${ }^{37}$ Due to the highly nonlinear objectives function, we content ourselves with checking the local optimality of a pooling contract. Actually, from Proposition 11, this local optimality of a pooling contract suffices to prove the benefits of bundling.

${ }^{38}$ From Proposition 9, this might require that $\Delta \theta$ is large enough.

${ }^{39}$ Unbundling is of course and by definition immune to the threat of such renegotiation.
} 
$\square \quad$ Welfare comparison. As we have seen screening possibilities disappear under bundling when either $\Delta \theta$ is small enough or when renegotiation is a concern. From a welfare point of view, the trade-off between organizational forms is then reduced to comparing the gains from bundling tasks, which better incentivizes the first-stage effort, and the costs of keeping pooling allocations at the operating stage, which weakens incentives for second-stage effort. The next proposition unveils that the trade-off can indeed go now against bundling.

Proposition 11. The following properties hold:

(i) When $\Delta \theta$ is small enough, bundling dominates.

(ii) When $\Delta \theta$ is large enough and renegotiation is a concern under bundling, unbundling dominates.

Under bundling, the compounding of asymmetric information ex post, moral hazard and renegotiation compel the use of pooling contracts that do not screen according to productivity shocks. For large operational risks, such pooling contracts are close to fixed payments which induce no operational effort. Under unbundling, it is easier to extract the information necessary to provide insurance and the revenue-sharing scheme is higher powered following a good shock. Unbundling still allows screening along productivity shocks and preserves some incentives at the operational stage when a high-productivity shock hits. It dominates bundling.

Instead, for small operational risks, asymmetric information is not a big deal. The possibility of screening the operator according to productivity shocks under unbundling does not yield much gain compared to the internalization of externalities that is possible under bundling, even though a pooling contract is needed in that case.

Bundling project phases is not always optimal, despite the presence of a positive externality across stages. For complex and risky projects, PPPs may refrain innovation and result in higher operational costs compared to unbundling. Innovation in complex projects brings about a level of risk that neither the authority nor the contractor wishes to bear. Asymmetric information makes it difficult to compensate the firms for events beyond its control. Risk is inefficiently shared and incentives at the operational stage are weakened. The fear that innovative approaches at the design stage create excessive risk-bearing later on also restrains the firm from innovating.

\section{The costs and benefits of private finance}

The interest of lenders in financing infrastructure projects for the provision of public services is explained by the stable returns, to a large extent uncorrelated with the market, that these investments generate. The interest of public authorities in private finance is a priori less clear. Existing evidence suggests that private finance has been sometimes employed more because of the urge to overcome budget and Maastricht Treaty constraints, or to gain political consent through strategic infrastructure programs, than because of efficiency considerations (IPPR, 2001). ${ }^{40}$ As private finance is often viewed as being more costly than public finance, the cost of this distortion might have been high.

However, an argument also often heard is that, with significant funds at risk, lenders and equity investors provide a level of rigor and due diligence to assessing project risks that may prove beneficial also to the public sector, especially when it lacks the knowledge and expertise to evaluate project risks rigorously on its own (Leahy, 2005). In practice, the existing costs and benefits of private finance have led governments to rely on private finance to various degrees. In DBFO models, for instance, the bundling of design and implementation comes with private finance, whereas in BOT models it does not: the facility is financed by the public sector and remains under public ownership throughout the contract.

${ }^{40}$ The Eurostat made a decision (news release 18/2004) on the accounting of PPPs to ensure homogeneity across member states and limit accounting tricks made to comply with the rules of the Stability and Growth Pact. 
In this section, we analyze the costs and benefits of private finance when there is bundling of design and implementation. We provide some insights on the relative advantages of the DBFO and BOT models of PPPs. To capture the benefits of the financier's expertise, we assume that the financier can observe and contract on the productivity shock whereas the public authority cannot. ${ }^{41}$ This assumption implies that the public authority proposes revenue-sharing schemes which are somewhat incomplete and do not depend on that shock.

A first benchmark for the present analysis is then given in Section 4, where bundling dominates when productivity shocks are observable by the public authority which also directly finances the investment. This case captures settings where the public authority has developed enough expertise. We will see below that this outcome can also be achieved by means of private finance even if the public authority does not hold such expertise. A second benchmark is given in Section 5. There, productivity shocks are unobservable by the public authority and, because of small uncertainty on those shocks or/and renegotiation, the public authority uses pooling contracts under bundling. This captures settings where the public authority has no expertise. Section 5 describes thus the outcome that is achieved without the financier's expertise.

To see the benefits of private finance, we now suppose that the public authority and the financier are two different entities taking moves sequentially. The firm must respond to the contracts offered by those two principals. Being a Stackelberg leader in the contracting game, the public authority first offers to the firm a compensation scheme $t(R)$. This contract does not stipulate any proviso to finance the investment $I$. Instead, the firm turns to its financier to cover this investment. The financial contract stipulates loans reimbursements $z(\theta, t(R))$ which depend on the realized productivity shock, commonly observed by the financier and the firm, and on the realized share of revenues captured by the firm. This financial contract is signed before productivity shocks realize.

For simplicity, we shall also assume that $\sigma^{2}=+\infty$, i.e., no quality index is available (equivalently, $\beta \equiv 0$ ). This assumption simplifies the analysis and keeps some symmetry between the principals: both can contract on the firm's revenues, the public authority to reward service provision and the financier to cover the investment. In this case, the analysis in Section 4 shows that the optimal revenue-sharing agreement has $\gamma_{B}^{*}=\frac{1+\frac{1}{\mu}}{1+\frac{1}{\mu}+r \eta^{2}}$ had shocks been verifiable. Bundling then achieves its greatest benefits.

Suppose now that the public authority has no expertise. Yet, it can still offer a compensation scheme of the form $t(R)=\alpha+\gamma R$ to incentivize the firm and keep the residual $R-t(R)$. This pooling contract is seemingly incomplete: it does not provide any insurance to the firm against productivity shocks and it does not allow any screening of these shocks.

Given such a compensation scheme, the financier uses his expertise to take all productivity risk and provide insurance to the firm. To do so, the financial contract stipulates (linear) statedependent reimbursements, which take the form

$$
z(\theta, t(R))=\zeta(\theta)+\varphi t(R) .^{42}
$$

This repayment is made of two pieces. The first one, $\zeta(\theta)$, is a state-contingent fixed repayment. The second component is a fixed fraction $(\varphi \in[0,1])$ of the firm's net revenue, which may be interpreted as an equity stake.

There is a simple contract that allows the public authority to exhaust all gains brought about by the financier's expertise. We develop the formal analysis in the Appendix and provide here just a sketch of the argument. Suppose that the public authority only asks the firm to pay a fixed entry

${ }^{41}$ De Bettignies and Ross (2009) also discuss the benefit of private finance in PPPs. In their model, information is symmetric but private finance may lead to the efficient termination of bad projects, while public developers may sustain such projects for political reasons.

${ }^{42}$ There is indeed no loss of generality in restricting the financial contract to a variable part which does not depend on $\theta$. The same arguments as those developed in Section 4 (see especially Lemma 1 in the Appendix) apply. We simplify presentation by imposing this (apparent) restriction up front. 
fee ( $\alpha_{B}$ being negative). This fee shifts the firm's payoff by a constant. With such a scheme, the financier becomes residual claimant for all other aspects of contracting. This is optimal because the risk-neutral financier ex ante holds the same information, and cares about how much revenues he can get from the venture, exactly as does the public authority in the scenario of Section 4. The financier therefore chooses the same incentive intensity $\gamma_{B}^{*}$ and provides the same level of insurance to the firm as what the public authority would do if it had the relevant expertise. This leads to an effort $a_{B}^{*}=\gamma_{B}^{*}$ in the first stage, exactly as in Section $4 .{ }^{43}$

The financier then reduces the fixed repayment $\zeta(\theta)$ to ensure that the firm can pay the entry fee and break even. The financier's expected profit (taking expectations over the possible realizations of $\theta$ ) is thus given by the social value of the project net of the investment outlay minus the entry fee paid to the public authority. The public authority can take advantage of its first-mover advantage by setting an entry fee that indirectly extracts all surplus from the financier. This fee is just equal to the social value of the project that could have been achieved if the public authority had expertise and directly provided insurance on top of inducing efforts:

$$
-\alpha_{B}=\frac{\left(1+\frac{1}{\mu}\right)^{2}}{2\left(1+\frac{1}{\mu}+r \eta^{2}\right)}-I .
$$

Proposition 12. Suppose that the financier has the expertise to observe $\theta$ whereas the public authority does not. Then, bundling dominates unbundling and the same outcome as if expertise was in the hands of the public authority can be achieved.

Using private finance brings additional costs over and above conventional funding. The cost of debt, which in the United Kingdom before the current credit crisis was about 1 percentage point (60-150 basis points) above the nominal cost of government borrowing, by 2009 was estimated to have risen to around 140-250 basis points (House of Lords, 2010) because of the credit crunch. The current cost of private finance raises issues about the benefit of PPP. If the private sector borrows capital at a higher interest rate than public authorities, the real cost of an investment $I$ becomes $(1+\rho) I$ for some $\rho>0$. Notwithstanding, Proposition 12 suggests that the benefits may still outweigh this cost if project risk is high $(\Delta \theta)$ and the financier has the expertise to evaluate project risks to an extent that public authorities cannot do. With expertise, the financier can help to improve upon risk allocation and reestablish the benefit of bundling. ${ }^{44}$

\section{Conclusion}

We have studied the agency costs of delegated project management, focusing on the link between the organizational form and the uncertainty that characterizes the project implementation. Our analysis has pointed at the efficiency gains that bundling of project planning and implementation can bring to a public sector seeking to delegate the provision of public services, but it has also emphasized how unbundling may be preferred when operational risks are high and informational asymmetries can create an undue advantage to the firm. In public procurement, our results suggest that contracting out through PPPs can yield potentially the highest benefit for services where uncertainty is limited or where sufficient past experience exists to inform the parties as to what may happen during operations so that an efficient risk allocation can be achieved. This also points out to the suitability of PPPs for services that have been traditionally

${ }^{43}$ Should effort $e$ generate social benefits beyond those captured by $R$, the financier's incentives would not be perfectly aligned with those of the public authority. Private finance would then still improve efficiency but not to the point of replicating the scenario of Section 4.

${ }^{44}$ In considering such extension where private finance is more costly, we assume that the public authority cannot rely on the financier's expertise if the latter has no stake in the project. In other words, relying on the financier's expertise and financing the investment itself is not an option. 
provided in-house under low-powered incentives but where the institutional context has changed creating scope for modernizing approaches, risks however remaining low. Examples include prison services and educational services.

Caution should instead be exerted when the public sector seeks to radically innovate on public service provision or to introduce new services where it lacks the knowledge or expertise to anticipate the impact of the innovative design/procedure/technology on the cost of operations. PPPs are less likely to deliver efficiency gains for highly innovative and complex services where risks are high and it is difficult for the public authority to commit to transfer such high risks to the private sector. However, to the extent that it is easier to predict contingencies that may arise during operations once the service has been already contracted out to the private sector, and thus that asymmetric information reduces over time, our analysis suggests that improvements in PPP contracting and performance should be observed over time.

An important issue that has been left out of the analysis is related to the procurement process for PPPs and how the uncertainty that characterizes service provision affects the costs of participating to the tender and thus the level of competitiveness in the contract award. Most PPP or PFI contracts are too complex to use the open or restricted procedure. In most PPPs, the contracting authority is unable to determine the technical specifications and the appropriate price level in advance. Therefore, until now the negotiated procedure has been the preferred solution for procuring PPP or PFI contracts. Current experience shows however that the procurement process for PPPs has been costly and time-consuming. Albeit with differences between sectors, it has been estimated that PPP tendering periods last an average of 34 months (NAO, 2007) and that procurement costs can reach $5 \%-10 \%$ of the capital cost of a project (Yescombe, 2007). ${ }^{45}$ Recently the European Commission introduced the Competitive Dialogues, a new procedure for PPPs contracts (EU Directive 2004/18/EC ) but doubts have emerged as to its suitability because of it being a complex and time-consuming procedure. More theoretical work should certainly be devoted to assessing the optimal form of the negotiation and bidding procedures for such complex projects. ${ }^{46}$

\section{Appendix}

The Appendix includes proofs of Propositions 1-9 and 11-12.

Proof of Proposition 1. Under unbundling, the principal's expected payoff is

$$
E_{\theta}((1-\gamma) e(\theta, \gamma, a))-\beta a-\alpha_{B}-\alpha_{O}-I .
$$

Taking into account the expressions the payoffs of the operator and of the builder, the principal's problem consists in maximizing expected net surplus minus risk premiums and any surplus left to the builder and the operator:

$$
\max _{\left(U_{B}, U_{O}(\cdot), \beta, \gamma\right)} E_{\theta}\left(e(\theta, \gamma, a)-\frac{\mu}{2}(e(\theta, \gamma, a)-a-\theta)^{2}\right)-\frac{a^{2}}{2}-\frac{r\left(\eta^{2}+\vartheta^{2}\right) \gamma^{2}}{2}-\frac{r \sigma^{2} \beta^{2}}{2}-U_{B}-U_{O}(a)-I,
$$

subject to (1), (2), (3) and (4). The two participation constraints (2) and (4) are binding. Inserting $U_{B}=U_{O}(a)=0$ and the expressions of efforts from (1) and (3) into the maximand, we must solve

$$
\max _{(\beta, \gamma)} \mathcal{W}_{U}(\beta, \gamma) \equiv \beta-\frac{\beta^{2}}{2}+\frac{1}{\mu}\left(\gamma-\frac{\gamma^{2}}{2}\right)-\frac{r\left(\eta^{2}+\vartheta^{2}\right) \gamma^{2}}{2}-\frac{r \sigma^{2} \beta^{2}}{2}-I .
$$

Optimizing immediately yields (5).

Proof of Proposition 2. Under bundling, the principal's expected payoff is

$$
E_{\theta}((1-\gamma) e(\theta, \gamma, a))-\beta a-\alpha-I .
$$

${ }^{45}$ These transaction costs are also to a large extent independent of the size of a project, which suffices to make PPP unsuitable for low-capital-value projects. HM Treasury (2006) in the United Kingdom currently considers PFI projects for less than $£ 20 \mathrm{~m}$ as poor value for money.

${ }^{46}$ Whether bundling or unbundling is optimal in a bidding context is an important issue that we have not touched upon in this work. Unbundling may indeed be optimal when some firms are better operators whereas others are better at the design stage. See Li (2011) for some work along these lines. 
Taking into account the expressions of the conglomerate's payoff, we obtain the following expression of the principal's problem:

$$
\max _{(U(a), \beta, \gamma)} E_{\theta}\left(e(\theta, \gamma, a)-\frac{\mu}{2}(e(\theta, \gamma, a)-a-\theta)^{2}\right)-\frac{a^{2}}{2}-\frac{r\left(\eta^{2}+\vartheta^{2}\right) \gamma^{2}}{2}-\frac{r \sigma^{2} \beta^{2}}{2}-U(a)-I,
$$

subject to (3), (6) and (7). Inserting the expressions of efforts at both stages given by (3) and (6) into the maximand and taking into account that (7) is binding, this optimization boils down to

$$
\max _{(\beta, \gamma)} \mathcal{W}_{B}(\beta, \gamma) \equiv \beta+\gamma-\frac{(\beta+\gamma)^{2}}{2}+\frac{1}{\mu}\left(\gamma-\frac{\gamma^{2}}{2}\right)-\frac{r\left(\eta^{2}+\vartheta^{2}\right) \gamma^{2}}{2}-\frac{r \sigma^{2} \beta^{2}}{2}-I .
$$

First-order conditions for optimality are

$$
\begin{gathered}
1-a=1-\beta-\gamma=r \sigma^{2} \beta, \\
1-a+\frac{1}{\mu}(1-\gamma)=r\left(\eta^{2}+\vartheta^{2}\right) \gamma .
\end{gathered}
$$

The optimal incentive intensities and first-stage effort in (8), (9) and (10) follow.

Q.E.D.

Proof of Proposition 3. First, observe that

$$
\max _{\beta} \mathcal{W}_{U}(\beta, \gamma)=\frac{1}{2\left(1+r \sigma^{2}\right)}+\frac{1}{\mu}\left(\gamma-\frac{\gamma^{2}}{2}\right)-\frac{r\left(\eta^{2}+\vartheta^{2}\right) \gamma^{2}}{2}-I,
$$

whereas

$$
\max _{\beta} \mathcal{W}_{B}(\beta, \gamma)=\gamma-\frac{\gamma^{2}}{2}+\frac{(1-\gamma)^{2}}{2\left(1+r \sigma^{2}\right)}+\frac{1}{\mu}\left(\gamma-\frac{\gamma^{2}}{2}\right)-\frac{r\left(\eta^{2}+\vartheta^{2}\right) \gamma^{2}}{2}-I .
$$

As $\gamma \in[0,1]$, we get:

$$
\Delta \mathcal{W}(\gamma)=\max _{\beta} \mathcal{W}_{B}(\beta, \gamma)-\max _{\beta} \mathcal{W}_{U}(\beta, \gamma)=\frac{r \sigma^{2}}{1+r \sigma^{2}}\left(\gamma-\frac{\gamma^{2}}{2}\right) \geq 0 .
$$

From this inequality, we immediately derive

$$
\max _{(\beta, \gamma)} \mathcal{W}_{B}(\beta, \gamma) \geq \max _{\beta} \mathcal{W}_{B}\left(\beta, \gamma_{U}\right)>\max _{\beta} \mathcal{W}_{U}\left(\beta, \gamma_{U}\right)=\max _{(\beta, \gamma)} \mathcal{W}_{U}(\beta, \gamma)
$$

where the strict inequality follows from the fact that $\gamma_{U} \in(0,1)$.

Proof of Proposition 4. Under unbundling, the principal's expected payoff writes as

$$
E_{\theta}\left((1-\gamma(\theta)) e(\theta, \gamma(\theta), a)-\alpha_{O}(\theta)\right)-\beta a-\alpha_{B}-I .
$$

Using the expressions of $U_{B}$ and $U_{O}(\theta, a)$ given in the text, the optimal contracts solve

$$
\max _{\left(a, U_{B}, U_{O}(\cdot), \beta, \gamma(\cdot)\right)} E_{\theta}\left(e(\theta, \gamma(\theta), a)-\frac{\mu}{2}(e(\theta, \gamma(\theta), a)-a-\theta)^{2}-\frac{a^{2}}{2}-\frac{r \sigma^{2} \beta^{2}}{2}-\frac{r \eta^{2} \gamma^{2}(\theta)}{2}-U_{O}(\theta, a)\right)-U_{B}-I,
$$

subject to (1), (2), (3) and (13). Both participation constraints (2) and (13) are binding at the optimum. (2) binding means $U_{B}=0$. From (13) binding and the strict concavity of $v(\cdot)$, it immediately follows that $U_{O}(\bar{\theta}, a)=U_{O}(\underline{\theta}, a)=0$. Inserting those expressions of the operator's and builder's payoffs into the maximand, we obtain

$$
\max _{(\beta, \gamma(\cdot))} \beta-\left(1+r \sigma^{2}\right) \frac{\beta^{2}}{2}+E_{\theta}\left(\frac{1}{\mu}\left(\gamma(\theta)-\frac{\gamma^{2}(\theta)}{2}\right)-\frac{r \eta^{2} \gamma^{2}(\theta)}{2}\right)-I .
$$

Optimizing with respect to $\gamma(\theta)$ and $\beta$ finally yields

$$
\begin{gathered}
\gamma_{U}^{*}(\bar{\theta})=\gamma_{U}^{*}(\underline{\theta})=\gamma_{U}^{*} \equiv \frac{\frac{1}{\mu}}{\frac{1}{\mu}+r \eta^{2}}>\gamma_{U}, \\
\beta_{B}^{*}=\beta_{U} \quad \text { and } \quad a_{B}^{*}=a_{U} .
\end{gathered}
$$

Because the operator is fully insured against productivity shocks, we obtain

$$
\alpha_{O}^{*}(\underline{\theta})-\alpha_{O}^{*}(\bar{\theta})=\gamma_{U}^{*} \Delta \theta>0 .
$$

For future reference (see the proof of Proposition 6), we define the principal's expected payoff with a mechanism with incentive intensities $\beta$ and $\gamma(\underline{\theta})=\gamma(\bar{\theta})=\gamma$ as

$$
\mathcal{W}_{U}^{*}(\beta, \gamma)=\beta-\left(1+r \sigma^{2}\right) \frac{\beta^{2}}{2}+\frac{1}{\mu}\left(\gamma-\frac{\gamma^{2}}{2}\right)-\frac{r \eta^{2} \gamma^{2}}{2}-I
$$


Proof of Proposition 5. We first prove the following lemma.

Lemma 1. Under bundling, there is no gain in making $\gamma$ depend on $\theta$ :

$$
\gamma(\bar{\theta})=\gamma(\underline{\theta})=\gamma .
$$

Proof. First, observe that the operator's payoff with a state-dependent contract is

$$
U_{O}(\theta, a)=\alpha(\theta)+\gamma(\theta)(a+\theta)+\left(\frac{1}{\mu}-r \eta^{2}\right) \frac{\gamma^{2}(\theta)}{2} .
$$

Using the CARA specification, the conglomerate's participation constraint (15) is

$$
U_{O}(\underline{\theta}, a)-\frac{1}{r} \ln \left(1-v+\operatorname{vexp}\left(-r\left(U_{O}(\bar{\theta}, a)-U_{O}(\underline{\theta}, a)\right)\right)\right) \geq 0 .
$$

Denoting $U_{O}(\theta, a)=\gamma(\theta) a+\tilde{U}_{O}(\theta), \Delta \gamma=\gamma(\bar{\theta})-\gamma(\underline{\theta})$ and $\Delta \tilde{U}_{O}=\tilde{U}_{O}(\bar{\theta})-\tilde{U}_{O}(\underline{\theta})$, this condition writes as

$$
(\beta+\gamma(\underline{\theta})) a-\frac{a^{2}}{2}-\frac{r \sigma^{2} \beta^{2}}{2}+\tilde{U}_{O}(\underline{\theta})-\frac{1}{r} \ln \left(1-v+\operatorname{vexp}\left(-r\left(a \Delta \gamma+\Delta \tilde{U}_{O}\right)\right)\right) \geq 0 .
$$

The left-hand side above is strictly concave in $a$. The first-order approach leads to the following expression of the conglomerate's incentive constraint in the first stage:

$$
a=\beta+\gamma(\underline{\theta})+\frac{v \Delta \gamma \exp \left(-r\left(a \Delta \gamma+\Delta \tilde{U}_{O}\right)\right)}{1-v+v \exp \left(-r\left(a \Delta \gamma+\Delta \tilde{U}_{O}\right)\right)} .
$$

The principal's expected payoff writes now

$$
E_{\theta}((1-\gamma(\theta)) e(\theta, \gamma(\theta), a)-\alpha(\theta))-\beta a-I .
$$

Using (3) and (A3), this expression can be rewritten as

$$
(1-\beta) a+E_{\theta}\left(\frac{1}{\mu}\left(\gamma(\theta)-\frac{\gamma^{2}(\theta)}{2}\right)-\frac{r \eta^{2} \gamma^{2}(\theta)}{2}-U_{O}(\theta, a)\right)-I .
$$

Recalling the definition of $U_{O}(\theta, a)$, we can rewrite the optimization problem

$$
\max _{(a, \beta, \gamma(\cdot) \tilde{U}(\cdot))}(1-\beta) a+E_{\theta}\left(\frac{1}{\mu}\left(\gamma(\theta)-\frac{\gamma^{2}(\theta)}{2}\right)-\frac{r \eta^{2} \gamma^{2}(\theta)}{2}\right)-v\left(a \Delta \gamma+\Delta \tilde{U}_{O}\right)-\gamma(\underline{\theta}) a-\tilde{U}_{O}(\underline{\theta})-I,
$$

subject to (A4) and (A5). Clearly, the participation constraint (A4) is binding. Inserting the expression of $\tilde{U}_{O}(\underline{\theta})$ so obtained into the maximand, we can rewrite the optimization problem as

$$
\begin{gathered}
\max _{(y, a, \beta, \gamma(\cdot))} a-\frac{a^{2}}{2}-\frac{r \sigma^{2} \beta^{2}}{2}+E_{\theta}\left(\frac{1}{\mu}\left(\gamma(\theta)-\frac{\gamma^{2}(\theta)}{2}\right)-\frac{r \eta^{2} \gamma^{2}(\theta)}{2}\right)+\varphi(y)-I, \\
\text { subject to } \quad a=\beta+\gamma(\underline{\theta})+\frac{v \Delta \gamma \exp (-r y)}{1-v+v \exp (-r y)},
\end{gathered}
$$

where we have introduced the new optimization variable

$$
y=a \Delta \gamma+\Delta \tilde{U}_{O}
$$

and defined the function

$$
\varphi(y)=-v y-\frac{1}{r} \ln (1-v+v \exp (-r y)) .
$$

Note that $\varphi(0)=0, \varphi^{\prime}(y)=-\frac{v(1-v)(1-\exp (-r y))}{1-\nu+\exp (-r y)}$, with in particular $\varphi^{\prime}(0)=0$.

Assuming concavity of the problem and denoting by $\lambda$ the multiplier of the incentive constraint (A7), the optimality conditions with respect to $a, \beta, \gamma(\bar{\theta}), \gamma(\underline{\theta})$ and $y$ are respectively given by

$$
\begin{gathered}
a=1-\lambda, \\
-r \sigma^{2} \beta+\lambda=0, \\
\frac{1}{\mu}(1-\gamma(\bar{\theta}))-r \eta^{2} \gamma(\bar{\theta})+\frac{\lambda \exp (-r y)}{1-v+v \exp (-r y)}=0, \\
\frac{1}{\mu}(1-\gamma(\underline{\theta}))-r \eta^{2} \gamma(\underline{\theta})+\frac{\lambda}{1-v+v \exp (-r y)}=0,
\end{gathered}
$$




$$
\varphi^{\prime}(y)-\frac{r v(1-v) \lambda \Delta \gamma \exp (r y)}{((1-v) \exp (r y)+v)^{2}}=0 .
$$

For $y=0,(\mathrm{~A} 10)$ and (A11) imply that $\gamma(\bar{\theta})=\gamma(\underline{\theta})=\gamma$ and thus $\Delta \gamma=0$. But then (A12) also holds at $y=0$ which shows that $y=0$ is optimal and that (A2) holds. This ends the proof of Lemma 1.

From Lemma 1, we get the simpler expression for $U_{O}(\theta, a)$ as

$$
U_{O}(\theta, a)=\alpha(\theta)+\gamma(a+\theta)+\left(\frac{1}{\mu}-r \eta^{2}\right) \frac{\gamma^{2}}{2} .
$$

Again from Lemma 1, and in particular the fact that $y=0$ is optimal, the participation constraint (A4) implies $\tilde{U}_{O}(\bar{\theta})=$ $\tilde{U}_{O}(\underline{\theta})=-\gamma a$. Thus $U_{O}(\bar{\theta}, a)=U_{O}(\underline{\theta}, a)$ such that

$$
\beta a-\frac{a^{2}}{2}-\frac{r \sigma^{2} \beta^{2}}{2}+U_{O}(\theta, a)=0 \quad \forall \theta \in \Theta,
$$

or, to put it differently,

$$
\alpha(\theta)+\gamma \theta+(\beta+\gamma) a-\frac{a^{2}}{2}-\frac{r \sigma^{2} \beta^{2}}{2}+\left(\frac{1}{\mu}-r \eta^{2}\right) \frac{\gamma^{2}}{2}=0 \quad \forall \theta \in \Theta .
$$

From which, we immediately deduce that

$$
\alpha(\underline{\theta})-\alpha(\bar{\theta})=\gamma \Delta \theta>0 .
$$

The first-order optimality conditions (A8), (A10) and (A11) immediately yield

$$
\begin{aligned}
& 1-a=1-\beta-\gamma=r \sigma^{2} \beta, \\
& 1-a+\frac{1}{\mu}(1-\gamma)=r \eta^{2} \gamma .
\end{aligned}
$$

From this, we derive the optimal incentive intensities:

$$
\beta_{B}^{*}=\frac{1}{1+r \sigma^{2}} \frac{r \eta^{2}}{\frac{1}{\mu}+\frac{r \sigma^{2}}{1+r \sigma^{2}}+r \eta^{2}}, \quad \text { and } \quad \gamma_{B}^{*}=\frac{\frac{1}{\mu}+\frac{r \sigma^{2}}{1+r \sigma^{2}}}{\frac{1}{\mu}+\frac{r \sigma^{2}}{1+r \sigma^{2}}+r \eta^{2}} .
$$

The optimal first stage effort level is now given by

$$
a_{B}^{*}=\frac{1+\gamma_{B}^{*} r \sigma^{2}}{1+r \sigma^{2}} .
$$

Comparing those variables with their values when $\theta$ is nonobservable is immediate.

For further reference (see the proof of Proposition 6), we rewrite the principal's optimization problem after having inserted the expression of $U_{O}(\theta, a)$ from (A13) as

$$
\max _{(a, \beta, \gamma)} a-\frac{a^{2}}{2}-\frac{r \sigma^{2} \beta^{2}}{2}+\frac{1}{\mu}\left(\gamma-\frac{\gamma^{2}}{2}\right)-\frac{r \eta^{2} \gamma^{2}}{2}-I,
$$

subject to (6), which amounts to

$$
\max _{(\beta, \gamma)} \mathcal{W}_{B}^{*}(\beta, \gamma) \equiv \beta+\gamma-\frac{(\beta+\gamma)^{2}}{2}+\frac{1}{\mu}\left(\gamma-\frac{\gamma^{2}}{2}\right)-\frac{r \eta^{2} \gamma^{2}}{2}-\frac{r \sigma^{2} \beta^{2}}{2}-I .
$$

Proof of Proposition 6. The proof is identical to that of Proposition 3. In $\operatorname{particular} \Delta W^{*}(\gamma) \equiv \max _{(\beta, \gamma)} \mathcal{W}_{B}^{*}(\beta, \gamma)-$ $\max _{(\beta, \gamma)} \mathcal{W}_{U}^{*}(\beta, \gamma)$ is as in expression (A1).

Proof of Proposition 7. To induce participation from the operator before he learns $\theta$, the ex ante participation constraint (13) must again be satisfied. At the same time, it is worth noticing that the first-stage effort still satisfies the incentive constraint (1). Under unbundling and asymmetric information, the optimal contract therefore solves

$$
\max _{\left(a, U_{B}, U_{O}(\cdot), \beta, \gamma(\cdot)\right)} E_{\theta}\left(e(\theta, \gamma(\theta), a)-\frac{\mu}{2}(e(\theta, \gamma(\theta), a)-a-\theta)^{2}-\frac{a^{2}}{2}-\frac{r \sigma^{2} \beta^{2}}{2}-\frac{r \eta^{2} \gamma^{2}(\theta)}{2}-U_{O}(\theta, a)\right)-U_{B}-I,
$$

subject to (1), (2), (3), (13) and (16). Both participation constraints (2) and (13) and the truth telling constraint (16) are binding at the optimum. (2) binding means $U_{B}=0$. The fact that both (13) and (16) are binding allows us to solve explicitly this system of equations for $\left(U_{O}(\bar{\theta}, a), U_{O}(\underline{\theta}, a)\right)$ thanks to the CARA specification. We get 


$$
\begin{aligned}
& U_{O}(\bar{\theta}, a)=\Delta \theta \gamma(\underline{\theta})+\frac{1}{r} \ln (1-v+v \exp (-r \Delta \theta \gamma(\underline{\theta}))), \\
& U_{O}(\underline{\theta}, a)=\frac{1}{r} \ln (1-v+v \exp (-r \Delta \theta \gamma(\underline{\theta}))) .
\end{aligned}
$$

Inserting those expressions of the builder's and the operator's payoffs into the maximand leads to the more compact expression of expected social welfare:

$$
\max _{(\beta, \gamma(\cdot))} \hat{W}_{U}(\beta, \gamma) \equiv \beta-\left(1+r \sigma^{2}\right) \frac{\beta^{2}}{2}+E_{\theta}\left(\frac{1}{\mu}\left(\gamma(\theta)-\frac{\gamma^{2}(\theta)}{2}\right)-\frac{r \eta^{2} \gamma^{2}(\theta)}{2}\right)+\varphi(\Delta \theta \gamma(\underline{\theta}))-I .
$$

Optimizing with respect $\beta$, we find $\hat{\beta}_{U}=\beta_{U}^{*}$. Therefore,

$$
\hat{a}_{U}=\hat{\beta}_{U}^{*}=a_{U}^{*}=\frac{1}{1+r \sigma^{2}} .
$$

Optimizing with respect to $\gamma(\bar{\theta})$, we find

$$
\hat{\gamma}_{U}(\bar{\theta})=\gamma_{U}^{*}=\frac{\frac{1}{\mu}}{\frac{1}{\mu}+r \eta^{2}} .
$$

This finally yields the following expression of the principal's expected payoff under unbundling (where we use the notation $\gamma=\gamma(\underline{\theta}))$ :

$$
\max _{\beta} \hat{W}_{U}(\beta, \gamma)=\frac{1}{2\left(1+r \sigma^{2}\right)}+\frac{v}{2 \mu\left(1+\mu r \eta^{2}\right)}+(1-v)\left(\frac{1}{\mu}\left(\gamma-\frac{\gamma^{2}}{2}\right)-\frac{r \eta^{2} \gamma^{2}}{2}\right)+\varphi(\Delta \theta \gamma)-I
$$

Optimizing with respect to $\gamma$, we finally get

$$
\hat{\gamma}_{U}(\underline{\theta})=\Phi\left(\Delta \theta, \hat{\gamma}_{U}(\underline{\theta})\right)
$$

where the function $\Phi(\Delta \theta, \gamma)=\frac{\frac{1}{\mu}-\frac{v \Delta \theta(1-\exp (-r \Delta \theta \gamma))}{1-v+\operatorname{vexp}(-r \Delta \theta \gamma)}}{\frac{1}{\mu}+r \eta^{2}}$ is strictly decreasing in $\gamma$. As we have $\Phi(\Delta \theta, 0)>0$ and $\Phi\left(\Delta \theta, \gamma_{U}^{*}\right)<\gamma_{U}^{*}$, then (A17) has a unique solution $\hat{\gamma}_{U}(\underline{\underline{\theta}}) \in\left(0, \gamma_{U}^{*}\right)$.

Q.E.D.

Proof of Proposition 8. Fix a level of first-stage effort $a$. Suppose that the principal wants to implement $a$ with revenuesharing schemes such that $\Delta \gamma>0$. (The case where the principals wants to implement this effort $a$ with a contract such that $\Delta \gamma=0$ at minimal agency costs is easy and will lead also to conditions (17) and (18) but rewritten under those specific circumstances.) From the analysis in the text, incentive compatibility implies

$$
U_{O}(\bar{\theta}, a)-U_{O}(\underline{\theta}, a)=\Delta \theta \gamma(\underline{\theta})+\xi
$$

for some $\xi>0$. Suppose that the agent deviates to an alternate effort $\tilde{a}$. When knowing ex post $\bar{\theta}$, the agent tells the truth whenever

$$
U_{O}(\bar{\theta}, a)+\gamma(\bar{\theta})(\tilde{a}-a) \geq U_{O}(\underline{\theta}, a)+\gamma(\underline{\theta})(\tilde{a}-a)+\Delta \theta \gamma(\underline{\theta})
$$

or alternatively when

$$
\tilde{a} \geq a-\frac{\xi}{\Delta \gamma} .
$$

Let us turn to the first-stage moral hazard incentive constraint. We consider only effort deviations that do not induce the firm to lie when hit by a bad shock; those deviations are thus sufficiently close to $a$ to avoid the countervailing problem mentioned in Footnote 35. We are thus describing a priori a larger set of implementable allocations.

In full generality, the first-stage moral hazard incentive constraint is still as in (14). This incentive constraint can be written in two different ways, depending on whether the first-stage effort deviation induces a lie or not in state $\bar{\theta}$.

(i) Consider first deviations such that $\tilde{a} \geq a-\frac{\xi}{\Delta \gamma}$. These deviations, which induce no lie, are dominated when the expected payoff of choosing $a$ satisfies

$$
\begin{aligned}
& \nu v\left(\beta a-\frac{a^{2}}{2}-\frac{r \sigma^{2} \beta^{2}}{2}+U_{O}(\bar{\theta}, a)\right)+(1-v) v\left(\beta a-\frac{a^{2}}{2}-\frac{r \sigma^{2} \beta^{2}}{2}+U_{O}(\underline{\theta}, a)\right) \\
& \geq \max _{\tilde{a} \geq a-\frac{\xi}{\Delta \gamma}} v v\left(\beta \tilde{a}-\frac{\tilde{a}^{2}}{2}-\frac{r \sigma^{2} \beta^{2}}{2}+U_{O}(\bar{\theta}, a)+\gamma(\bar{\theta})(\tilde{a}-a)\right) \\
& \quad+(1-v) v\left(\beta \tilde{a}-\frac{\tilde{a}^{2}}{2}-\frac{r \sigma^{2} \beta^{2}}{2}+U_{O}(\underline{\theta}, a)+\gamma(\underline{\theta})(\tilde{a}-a)\right) .
\end{aligned}
$$


Taking into account (A18) gives us a condition written in terms of certainty equivalents

$$
\begin{aligned}
& \beta a-\frac{a^{2}}{2}-\frac{r \sigma^{2} \beta^{2}}{2}+U_{O}(\underline{\theta}, a)-\frac{1}{r} \ln (1-v+v \exp (-r(\Delta \theta \gamma(\underline{\theta})+\xi))) \\
& \geq \max _{\tilde{a} \geq a-\frac{\xi}{\Delta \gamma}} \beta \tilde{a}-\frac{\tilde{a}^{2}}{2}-\frac{r \sigma^{2} \beta^{2}}{2}+\gamma(\underline{\theta})(\tilde{a}-a)+U_{O}(\underline{\theta}, a)-\frac{1}{r} \ln (1-v+v \exp (-r(\Delta \gamma(\tilde{a}-a)+\Delta \theta \gamma(\underline{\theta})+\xi)))
\end{aligned}
$$

or simplifying

$$
\begin{aligned}
& \beta a-\frac{a^{2}}{2}-\frac{1}{r} \ln (1-v+v \exp (-r(\Delta \theta \gamma(\underline{\theta})+\xi))) \\
& \geq \max _{\tilde{a} \geq a-\frac{\xi}{\Delta \gamma}} \beta \tilde{a}-\frac{\tilde{a}^{2}}{2}+\gamma(\underline{\theta})(\tilde{a}-a)-\frac{1}{r} \ln (1-v+\operatorname{vexp}(-r(\Delta \gamma(\tilde{a}-a)+\Delta \theta \gamma(\underline{\theta})+\xi))) .
\end{aligned}
$$

The maximand on the right-hand side is concave in $\tilde{a}$ because $\Delta \gamma \geq 0$ (a standard monotonicity condition coming from adding up truth-telling constraints in state $\bar{\theta}$ and $\underline{\theta}$ when effort $a$ is undertaken). ${ }^{47}$ The maximum must also be achieved at $a$ by definition. The first-order condition for optimality evaluated at $\tilde{a}=a$ is

$$
a=\beta+\frac{\nu \gamma(\bar{\theta})+(1-v) \gamma(\underline{\theta}) \exp (r(\Delta \theta \gamma(\underline{\theta})+\xi))}{\nu+(1-v) \exp (r(\Delta \theta \gamma(\underline{\theta})+\xi))} .
$$

(ii) Consider now deviations such that $\tilde{a} \leq a-\frac{\xi}{\Delta \gamma}$. These deviations which induce a lie in state $\bar{\theta}$, are dominated when

$$
\begin{aligned}
& \nu v\left(\beta a-\frac{a^{2}}{2}-\frac{r \sigma^{2} \beta^{2}}{2}+U_{O}(\bar{\theta}, a)\right)+(1-v) v\left(\beta a-\frac{a^{2}}{2}-\frac{r \sigma^{2} \beta^{2}}{2}+U_{O}(\underline{\theta}, a)\right) \\
& \geq \max _{\tilde{a} \leq a-\frac{\xi}{\Delta \gamma}} v v\left(\beta \tilde{a}-\frac{\tilde{a}^{2}}{2}-\frac{r \sigma^{2} \beta^{2}}{2}+U_{O}(\underline{\theta}, a)+\gamma(\underline{\theta})(\tilde{a}-a)+\Delta \theta \gamma(\underline{\theta})\right) \\
& \quad+(1-v) v\left(\beta \tilde{a}-\frac{\tilde{a}^{2}}{2}-\frac{r \sigma^{2} \beta^{2}}{2}+U_{O}(\underline{\theta}, a)+\gamma(\underline{\theta})(\tilde{a}-a)\right) .
\end{aligned}
$$

Taking again into account (A18) and using certainty equivalents, we get

$$
\begin{aligned}
& \beta a-\frac{a^{2}}{2}-\frac{1}{r} \ln (1-v+v \exp (-r(\Delta \theta \gamma(\underline{\theta})+\xi))) \\
& \geq \max _{\tilde{a} \leq a-\frac{\xi}{\Delta \gamma}} \beta \tilde{a}-\frac{\tilde{a}^{2}}{2}+\gamma(\underline{\theta})(\tilde{a}-a)-\frac{1}{r} \ln (1-v+v \exp (-r(\Delta \theta \gamma(\underline{\theta})))) .
\end{aligned}
$$

Suppose first that $\beta+\gamma(\underline{\theta})<a-\frac{\xi}{\Delta \gamma}$. The maximum on the right-hand side of (A21) is achieved for $\beta+\gamma(\underline{\theta})$. (A21) becomes

$$
\frac{1}{r} \ln (1-v+v \exp (-r(\Delta \theta \gamma(\underline{\theta})))) \geq \frac{1}{2}(\beta+\gamma(\underline{\theta})-a)^{2}+\frac{1}{r} \ln (1-v+v \exp (-r(\Delta \theta \gamma(\underline{\theta})+\xi))) .
$$

Using the expression for $a$ from (A20) yields

$$
\begin{aligned}
& \frac{1}{r} \ln (1-v+v \exp (-r(\Delta \theta \gamma(\underline{\theta})))) \\
& \quad \geq \frac{1}{2} \frac{v^{2}(\Delta \gamma)^{2}}{(v+(1-v) \exp (r(\Delta \theta \gamma(\underline{\theta})+\xi)))^{2}}+\frac{1}{r} \ln (1-v+v \exp (-r(\Delta \theta \gamma(\underline{\theta})+\xi))) .
\end{aligned}
$$

The right-hand side of (A22) is decreasing in $\xi$, and greater (resp. lower) than the left-hand side for $\xi=0$ if $\Delta \gamma>$ 0 (resp. $\xi=+\infty)$. Hence, there is a unique $\xi(\gamma(\underline{\theta}), \Delta \gamma)(\xi(\gamma(\underline{\theta}), \Delta \gamma)>0$ if $\Delta \gamma>0)$ such that

$$
\frac{1}{r} \ln \left(\frac{1-v+v \exp (-r(\Delta \theta \gamma(\underline{\theta})))}{1-v+v \exp (-r(\Delta \theta \gamma(\underline{\theta})+\xi(\gamma(\underline{\theta}, \Delta \gamma))))}\right)=\frac{1}{2} \frac{v^{2}(\Delta \gamma)^{2}}{(v+(1-v) \exp (r(\Delta \theta \gamma(\underline{\theta})+\xi(\gamma(\underline{\theta}), \Delta \gamma))))^{2}} .
$$

Therefore, (A22) can now be written as

$$
\xi \geq \xi(\gamma(\underline{\theta}), \Delta \gamma)
$$

Note that $\xi(\gamma(\underline{\theta}), 0)=0, \xi(\gamma(\underline{\theta}), \Delta \gamma) \approx_{\Delta \gamma \approx 0} \frac{1}{2} \frac{\nu(\Delta \gamma)^{2}}{\nu+(1-v) \exp (r(\Delta \theta \gamma(\theta)))}$. From there, it follows that $\left.\frac{\partial \xi}{\partial \Delta \gamma}\right|_{\Delta \gamma=0}=$ $\left.\frac{\partial \xi}{\partial \gamma(\underline{\theta})}\right|_{\Delta \gamma=0}=0$.

${ }^{47}$ See, for instance, Laffont and Martimort (2002, Chapter 2). 
Suppose a contrario that $\beta+\gamma(\underline{\theta}) \geq a-\frac{\xi}{\Delta \gamma}$. Then, the maximum on the right-hand side of (A21) is at $a-\frac{\xi}{\Delta \gamma}$ and (A21) becomes

$$
\frac{\xi}{\Delta \gamma}\left(\frac{\xi}{2 \Delta \gamma}+\beta+\gamma(\underline{\theta})-a\right) \geq \frac{1}{r} \ln \left(\frac{1-v+v \exp (-r(\Delta \theta \gamma(\underline{\theta})+\xi))}{1-v+v \exp (-r(\Delta \theta \gamma(\underline{\theta})))}\right) .
$$

Using the expression for $a$ from (A20) yields a condition

$$
\frac{\xi^{2}}{2(\Delta \gamma)^{2}} \geq H(\xi)=\frac{k \xi}{k+(1-k) \exp (r \xi)}+\frac{1}{r} \ln (1+k(\exp (-r \xi)-1)),
$$

where $k=\frac{v}{v+(1-v) \exp (r(\Delta \theta \gamma(\theta)))}<1$. Observe that $H(0)=0, H^{\prime}(\xi)=-\frac{r k(1-k) \xi \exp (r \xi)}{(k+(1-k) \exp (r \xi))^{2}}<0$ while $\frac{\xi^{2}}{2(\Delta \gamma)^{2}}$ is increasing and thus (A24) always holds. Hence, choosing $\tilde{a}=a-\frac{\xi}{\Delta \gamma}$ when $a$ is given by (A20) is actually dominated.

Let us turn to the principal's problem. The objective writes again as in (A6) so that the principal's problem becomes thus

$$
\max _{\left(a, U_{O}(\cdot), \beta, \gamma(\cdot), \xi\right)}(1-\beta) a+E_{\theta}\left(\frac{1}{\mu}\left(\gamma(\theta)-\frac{\gamma^{2}(\theta)}{2}\right)-\frac{r \eta^{2} \gamma^{2}(\theta)}{2}-U_{O}(\theta, a)\right)-I,
$$

subject to (13), (A18), (A20) and (A23). Both the participation constraint (13) and the truth-telling constraint (A18) are binding. The CARA specification allows us to solve explicitly these two equations for $\left(U_{O}(\bar{\theta}, a), U_{O}(\underline{\theta}, a)\right)$ and get the following expressions of the firm's payoff for each $\theta$ :

$$
\begin{aligned}
& \beta a-\frac{a^{2}}{2}-\frac{r \sigma^{2} \beta^{2}}{2}+U_{O}(\bar{\theta}, a)=\Delta \theta \gamma(\underline{\theta})+\xi+\frac{1}{r} \ln (1-v+v \exp (-r(\Delta \theta \gamma(\underline{\theta})+\xi))), \\
& \beta a-\frac{a^{2}}{2}-\frac{r \sigma^{2} \beta^{2}}{2}+U_{O}(\underline{\theta}, a)=\frac{1}{r} \ln (1-v+v \exp (-r(\Delta \theta \gamma(\underline{\theta})+\xi))) .
\end{aligned}
$$

Inserting those expressions into the maximand leads to a more compact expression:

$$
\max _{(\beta, \gamma(\cdot), \xi)} a-\frac{a^{2}}{2}-\frac{r \sigma^{2} \beta^{2}}{2}+E_{\theta}\left(\frac{1}{\mu}\left(\gamma(\theta)-\frac{\gamma^{2}(\theta)}{2}\right)-\frac{r \eta^{2} \gamma^{2}(\theta)}{2}\right)+\varphi(\Delta \theta \gamma(\underline{\theta})+\xi)-I,
$$

subject to (A20) and (A23). The above objective is decreasing in $\xi$. Moreover, from (A20), $a$ is also decreasing in $\xi$ and so is $a-\frac{a^{2}}{2}$ as long as $a<1$, a condition that is satisfied on the solution as we will see. Henceforth, (A23) is binding. Inserting this expression into (A20) yields (18).

Q.E.D.

Proof of Proposition 9. Under bundling, the principal's optimization problem is

$$
\begin{gathered}
\max _{(\beta, \gamma(\theta), \Delta \gamma \geq 0)} a-\frac{a^{2}}{2}-\frac{r \sigma^{2} \beta^{2}}{2}+v\left(\frac{1}{\mu}\left(\gamma(\underline{\theta})+\Delta \gamma-\frac{(\gamma(\underline{\theta})+\Delta \gamma)^{2}}{2}\right)-\frac{r \eta^{2}(\gamma(\underline{\theta})+\Delta \gamma)^{2}}{2}\right) \\
+(1-v)\left(\frac{1}{\mu}\left(\gamma(\underline{\theta})-\frac{\gamma^{2}(\underline{\theta})}{2}\right)-\frac{r \eta^{2} \gamma^{2}(\underline{\theta})}{2}\right)+\varphi(\Delta \theta \gamma(\underline{\theta})+\xi(\gamma(\underline{\theta}), \Delta \gamma))-I,
\end{gathered}
$$

subject to (18). We are going to show that a pooling contract is locally optimal when $\Delta \theta$ is small.

Inserting $a$ from (18) into the maximand yields an expression in $(\beta, \gamma(\underline{\theta}), \Delta \gamma)$, namely,

$$
\begin{aligned}
\hat{W}_{B}(\beta, \gamma(\underline{\theta}), \Delta \gamma)= & a(\beta, \gamma(\underline{\theta}), \Delta \gamma)-\frac{a^{2}(\beta, \gamma(\underline{\theta}), \Delta \gamma)}{2}-\frac{r \sigma^{2} \beta^{2}}{2}+\varphi(\Delta \theta \gamma(\underline{\theta})+\xi(\gamma(\underline{\theta}), \Delta \gamma))-I \\
& +v\left(\frac{1}{\mu}\left(\gamma(\underline{\theta})+\Delta \gamma-\frac{(\gamma(\underline{\theta})+\Delta \gamma)^{2}}{2}\right)-\frac{r \eta^{2}(\gamma(\underline{\theta})+\Delta \gamma)^{2}}{2}\right) \\
& +(1-v)\left(\frac{1}{\mu}\left(\gamma(\underline{\theta})-\frac{\gamma^{2}(\underline{\theta})}{2}\right)-\frac{r \eta^{2} \gamma^{2}(\underline{\theta})}{2}\right) .
\end{aligned}
$$

Taking the first-order derivatives of $\hat{W}_{B}(\beta, \gamma(\underline{\theta}), \Delta \gamma)$ with respect to $\beta, \Delta \gamma$ and $\gamma(\underline{\theta})$ evaluated at $\Delta \gamma=0$ and using $\xi(\gamma(\underline{\theta}), 0)=\left.\frac{\partial \xi}{\partial \Delta \gamma}\right|_{\Delta \gamma=0}=\left.\frac{\partial \xi}{\partial \gamma(\underline{\theta})}\right|_{\Delta \gamma=0}=0$, we get

$$
\begin{gathered}
\frac{\partial \hat{W}_{B}}{\partial \beta}(\beta, \gamma(\underline{\theta}), 0)=1-a(\beta, \gamma(\underline{\theta}), 0)-r \sigma^{2} \beta, \\
\frac{\partial \hat{W}_{B}}{\partial \Delta \gamma}(\beta, \gamma(\underline{\theta}), 0)=v\left(\frac{1-a(\beta, \gamma(\underline{\theta}), 0)}{v+(1-v) \exp (r \Delta \theta \gamma(\underline{\theta}))}+\frac{1-\gamma(\underline{\theta})}{\mu}-r \eta^{2} \gamma(\underline{\theta})\right), \\
\frac{\partial \hat{W}_{B}}{\partial \gamma(\underline{\theta})}(\beta, \gamma(\underline{\theta}), 0)=1-a(\beta, \gamma(\underline{\theta}), 0)+\frac{1-\gamma(\underline{\theta})}{\mu}-r \eta^{2} \gamma(\underline{\theta})-\frac{v(1-v) \Delta \theta(1-\exp (-r \Delta \theta \gamma(\underline{\theta})))}{1-v+v \exp (-r \Delta \theta \gamma(\underline{\theta}))} .
\end{gathered}
$$


For an interior solution in $\gamma(\underline{\theta})$ corresponding to an optimum with $\Delta \gamma=0$, we must have $\frac{\partial \hat{W}_{B}}{\partial \gamma(\underline{\underline{\theta}})}(\beta, \gamma(\underline{\theta}), 0)=0$. Using (A27), we can then simplify the expression of $\frac{\partial \hat{W}_{B}}{\partial \Delta \gamma}(\beta, \gamma(\underline{\theta}), 0)$ in (A26) and obtain for such interior solution

$$
\frac{\partial \hat{W}_{B}}{\partial \Delta \gamma}(\beta, \gamma(\underline{\theta}), 0)=\frac{v(1-v)(1-\exp (-r \Delta \theta \gamma(\underline{\theta})))}{1-v+v \exp (-r \Delta \theta \gamma(\underline{\theta}))}(\nu \Delta \theta-(1-a(\beta, \gamma(\underline{\theta}), 0))) .
$$

Hence, $\frac{\partial \hat{W}_{B}}{\partial \Delta \gamma}(\beta, \gamma(\underline{\theta}), 0)<0$ when $\Delta \theta$ is small enough (notice indeed that (A26) and the analysis below of the pooling case $\gamma=\gamma(\bar{\theta})=\gamma(\underline{\theta})$ altogether imply that $1-a(\beta, \gamma(\underline{\theta}), 0)$ is close to $1-a_{B}^{*}=\frac{r \sigma^{2}}{1+r \sigma^{2}}\left(1-\gamma_{B}^{*}\right)>0$ so that the right-hand side of (A28) is strictly negative when $\Delta \theta$ is small enough). Then, $\Delta \gamma=0$ is a local optimum.

With such a pooling contract and denoting $\gamma=\gamma(\bar{\theta})=\gamma(\underline{\theta})$ (notice that the analysis of this pooling case is also relevant for the case of renegotiation-proof contracts where $\Delta \theta$ might be arbitrary), the principal's problem becomes

$$
\max _{(\beta, \gamma)} a-\frac{a^{2}}{2}-\frac{r \sigma^{2} \beta^{2}}{2}+\frac{1}{\mu}\left(\gamma-\frac{\gamma^{2}}{2}\right)-\frac{r \eta^{2} \gamma^{2}}{2}+\varphi(\Delta \theta \gamma)-I,
$$

subject to (6). Inserting the constraint into the maximand, we define

$$
\hat{W}_{B}(\beta, \gamma)=\beta+\gamma-\frac{(\beta+\gamma)^{2}}{2}-\frac{r \sigma^{2} \beta^{2}}{2}+\frac{1}{\mu}\left(\gamma-\frac{\gamma^{2}}{2}\right)-\frac{r \eta^{2} \gamma^{2}}{2}+\varphi(\Delta \theta \gamma)-I .
$$

Optimizing first with respect to $\beta$, we find an optimal value

$$
\beta=\frac{1-\gamma}{1+r \sigma^{2}}
$$

Note that

$$
\max _{\beta} \hat{W}_{B}(\beta, \gamma)=\frac{1}{2\left(1+r \sigma^{2}\right)}+\frac{r \sigma^{2}}{1+r \sigma^{2}}\left(\gamma-\frac{\gamma^{2}}{2}\right)+\frac{1}{\mu}\left(\gamma-\frac{\gamma^{2}}{2}\right)-\frac{r \eta^{2} \gamma^{2}}{2}+\varphi(\Delta \theta \gamma)-I .
$$

Optimizing with respect to $\gamma$ finally yields the following implicit definition of $\hat{\gamma}_{B}$ :

$$
\hat{\gamma}_{B}=\Psi\left(\Delta \theta, \hat{\gamma}_{B}\right)
$$

where $\Psi(\Delta \theta, \gamma)=\frac{\frac{1}{\mu}+\frac{r \sigma^{2}}{1+r \sigma^{2}}-\frac{v(1-v) \Delta \theta(1-\exp (-r \Delta \theta \gamma))}{1-v+v e x p(-r \Delta \theta \gamma)}}{\frac{1}{\mu}+\frac{r \sigma^{2}}{1+r \sigma^{2}}+r \eta^{2}}$ is decreasing in $\gamma$. Because $\Psi(\Delta \theta, 0)>0$ and $\Psi(\Delta \theta, 1)<\frac{\frac{1}{\mu}+\frac{r \sigma^{2}}{1+r \sigma^{2}}}{\frac{1}{\mu}+\frac{r \sigma^{2}}{1+r \sigma^{2}}+r \eta^{2}}<1$, (A30) has a unique solution $\hat{\gamma}_{B}^{\frac{1}{1+r \sigma^{2}}} \in(0,1)$. We check that

$$
\hat{\gamma}_{B}<\gamma_{B}^{*}
$$

Because $\Psi(\Delta \theta, \gamma)>\Phi(\Delta \theta, \gamma)$, the implicit solutions to (A17) and (A30) are such that

$$
\hat{\gamma}_{B}>\hat{\gamma}_{U} .
$$

The optimal effort is finally

$$
\hat{a}_{B}=\frac{1+r \sigma^{2} \hat{\gamma}_{B}}{1+r \sigma^{2}}<a_{B}
$$

For further references (see below the proof of Proposition 11), observe that $\Psi(\Delta \theta, \gamma)$ is strictly decreasing in $\Delta \theta$. Hence, $\hat{\gamma}_{B}$ is a decreasing function of $\Delta \theta$ that converges toward 0 as $\Delta \theta$ goes to $\infty$. Provided that $\Delta \theta \hat{\gamma}_{B}$ converges also toward zero as $\Delta \theta$ goes to $\infty$, a Taylor approximation of the right-hand side of (A30) yields

$$
\hat{\gamma}_{B} \underset{\Delta \theta \rightarrow+\infty}{\approx} \frac{\frac{1}{\mu}+\frac{r \sigma^{2}}{1+r \sigma^{2}}-r v(1-v)(\Delta \theta)^{2} \hat{\gamma}_{B}}{\frac{1}{\mu}+\frac{r \sigma^{2}}{1+r \sigma^{2}}+r \eta^{2}} .
$$

Finally, we obtain the following approximation

$$
\hat{\gamma}_{B} \underset{\Delta \theta \rightarrow+\infty}{\approx} \frac{\frac{1}{\mu}+\frac{r \sigma^{2}}{1+r \sigma^{2}}}{r v(1-v) \Delta \theta^{2}} .
$$

In particular,

$$
\lim _{\Delta \theta \rightarrow+\infty} \Delta \theta \hat{\gamma}_{B}=0 .
$$


Proof of Proposition 11. Remember that, under bundling and when either $\Delta \theta$ is small enough or if one insists on renegotiation-proof contracts, the principal's welfare expressed as a function of $\gamma=\gamma(\underline{\theta})$ writes as (A29) whereas it is (A16) under unbundling. From this it immediately follows that

$$
\begin{aligned}
\Delta \hat{\mathcal{W}}(\gamma) & =\max _{\beta} \hat{\mathcal{W}}_{B}(\beta, \gamma)-\max _{\beta} \hat{\mathcal{W}}_{U}(\beta, \gamma) \\
& =\frac{r \sigma^{2}}{1+r \sigma^{2}}\left(\gamma-\frac{\gamma^{2}}{2}\right)+v\left(\frac{1}{\mu}\left(\gamma-\frac{\gamma^{2}}{2}\right)-\frac{r \eta^{2} \gamma^{2}}{2}-\frac{1}{2 \mu\left(1+\mu r \eta^{2}\right)}\right) .
\end{aligned}
$$

This quadratic function is negative in the neighborhood of $\gamma=0$ and positive when $\gamma$ is close to $\gamma_{U}^{*}$. It has a unique root in $\left(0, \gamma_{U}^{*}\right)$. When $\Delta \theta$ is small enough, $\hat{\gamma}_{U}$ is close to $\gamma_{U}^{*}$ and thus $\Delta \hat{\mathcal{W}}\left(\hat{\gamma}_{U}\right)>0$. This in turn implies $\max _{(\beta, \gamma)} \hat{\mathcal{W}}_{B}(\beta, \gamma)>\max _{(\beta, \gamma)} \hat{\mathcal{W}}_{U}(\beta, \gamma)$ and bundling dominates.

When instead $\Delta \theta$ is large enough, (A32) implies that

$$
\lim _{\Delta \theta \rightarrow+\infty} \Delta \hat{\mathcal{W}}\left(\hat{\gamma}^{B}\right)=-\frac{v}{2 \mu\left(1+\mu r \eta^{2}\right)}<0
$$

and unbundling dominates.

Q.E.D.

Proof of Proposition 12. When accepting both the financial and the public contracts, the firm gets a certainty equivalent payoff in state $\theta$ which can be written as:

$$
-\zeta(\theta)+(1-\varphi)(\alpha+\gamma e)-\frac{r(1-\varphi)^{2} \gamma^{2} \eta^{2}}{2}-\frac{\mu}{2}(e-a-\theta)^{2}-\frac{a^{2}}{2} .
$$

From this, it immediately follows that the operational effort in state $\theta$ becomes

$$
e(\theta,(1-\varphi) \gamma, a)=a+\theta+\frac{(1-\varphi) \gamma}{\mu} .
$$

Using (A33), the firm's expected payoff when signing the financial contract is

$$
E_{\theta}\left(v\left(-\zeta(\theta)+(1-\varphi)(\alpha+\gamma(a+\theta))+\frac{(1-\varphi)^{2} \gamma^{2}}{2}\left(\frac{1}{\mu}-r \eta^{2}\right)-\frac{a^{2}}{2}\right)\right) .
$$

Following arguments similar to those developed in the proof of Proposition 5, the financier provides full insurance to the firm against the productivity shock $\theta$ :

$$
-\zeta(\bar{\theta})+(1-\varphi) \gamma \bar{\theta}=-\zeta(\underline{\theta})+(1-\varphi) \gamma \underline{\theta}=-Z .
$$

From there, we can rewrite the certainty equivalent of the firm's expected payoff as

$$
-Z+(1-\varphi)(\alpha+\gamma a)+\frac{(1-\varphi)^{2} \gamma^{2}}{2}\left(\frac{1}{\mu}-r \eta^{2}\right)-\frac{a^{2}}{2},
$$

which is maximized when the following first-stage incentive constraint holds:

$$
a=(1-\varphi) \gamma .
$$

The firm's participation constraint when accepting public and financial contracts is

$$
-Z+(1-\varphi)(\alpha+\gamma a)+\frac{(1-\varphi)^{2} \gamma^{2}}{2}\left(\frac{1}{\mu}-r \eta^{2}\right)-\frac{a^{2}}{2} \geq 0 .
$$

For a given compensation scheme offered by the public authority, the financier designs a financial contract that maximizes his expected net return from the project

$$
\max _{(\varphi, Z)} E_{\theta}(\varphi(\alpha+\gamma e(\theta,(1-\varphi) \gamma, a)))+Z-I
$$

subject to (A33), (A35) and (A36). Of course, (A36) is binding, which leads to rewriting the financier's problem as

$$
\max _{\varphi} E_{\theta}\left(\alpha+\gamma^{2}\left((1-\varphi)\left(1+\frac{1}{\mu}\right)-\frac{(1-\varphi)^{2}}{2}\left(1+\frac{1}{\mu}+r \eta^{2}\right)\right)\right) .
$$

The solution $\varphi^{*}$ to this problem is readily obtained as

$$
\begin{gathered}
1-\varphi^{*}=\gamma_{B}^{*}, \\
a=\gamma_{B}^{*} \gamma .
\end{gathered}
$$

This leads to the expressions of the financier's payoff and break-even constraint:

$$
\alpha+\gamma^{2}\left(\gamma_{B}^{*}\left(1+\frac{1}{\mu}\right)-\frac{\left(\gamma_{B}^{*}\right)^{2}}{2}\left(1+\frac{1}{\mu}+r \eta^{2}\right)\right)-I \geq 0 .
$$

(C) RAND 2012 . 
Turning to the public authority's problem, the optimal compensation scheme solves

$$
\max _{(\alpha, \gamma)} E_{\theta}\left(-\alpha+(1-\gamma) e\left(\theta, \gamma_{B}^{*} \gamma, \gamma_{B}^{*} \gamma\right)\right)
$$

subject to (A37) and (A39). Of course, (A39) is binding, which leads to rewriting the public authority's problem as

$$
\max _{\gamma} \gamma \gamma_{B}^{*}\left(1+\frac{1}{\mu}\right)-\frac{\gamma^{2}\left(\gamma_{B}^{*}\right)^{2}}{2}\left(1+\frac{1}{\mu}+r \eta^{2}\right)-I .
$$

The above maximand is obtained for $\gamma=1$. This shows that the financier ends up being a residual claimant for the provision of incentives.

The financier's expected payoff (taking expectations over the possible realizations of $\theta$ ) is then the social value of the project net of course of the investment and the entry fee paid to the public authority. We get

$$
\gamma_{B}^{*}\left(1+\frac{1}{\mu}\right)-\frac{\left(\gamma_{B}^{*}\right)^{2}}{2}\left(1+\frac{1}{\mu}+r \eta^{2}\right)-I+\alpha_{B} .
$$

The public authority chooses the fee $\alpha_{B}$ so that the expert financier breaks even:

$$
-\alpha_{B}=\gamma_{B}^{*}\left(1+\frac{1}{\mu}\right)-\frac{\left(\gamma_{B}^{*}\right)^{2}}{2}\left(1+\frac{1}{\mu}+r \eta^{2}\right)-I \equiv \frac{\left(1+\frac{1}{\mu}\right)^{2}}{2\left(1+\frac{1}{\mu}+r \eta^{2}\right)}-I .
$$

\section{References}

Aghion, P. And Tirole, J. “The Management of Innovation.” Quarterly Journal of Economics, Vol. 109 (1994), pp. 1185-1209.

BaKer, G. And Jorgensen, B. "Volatility, Noise and Incentives.” Mimeo, Harvard University, 2003.

BAJARI, P. AND TADELIS, S. "Incentives versus Transaction Costs: A Theory of Procurement Contracts." The RAND Journal of Economics, Vol. 32 (2001), pp. 387-407.

Baliga, S. AND SJöström, T. "Decentralization and Collusion.” Journal of Economic Theory, Vol. 104 (1998), pp. 525-536.

BARON, D. AND BESANKO, D. "Information, Control and Organizational Structure." Journal of Economics and Management Strategy, Vol. 1 (1992), pp. 237-275.

— AND ——. "Informational Alliance." Review of Economic Studies, Vol. 66 (1999), pp. 743-768.

Bennett, J. And Iossa, E. "Building and Managing Facilities for Public Services." Journal of Public Economics, Vol. 90 (2006), pp. 2143-2160.

Besley, T. and Ghatak, M. "Government versus Private Ownership of Public Goods." Quarterly Journal of Economics, Vol. 116 (2001), pp. 1343-1372.

Che, Y.K. And Yoo, S. “Optimal Incentives for Teams.” American Economic Review, Vol. 91 (2001), pp. 525-541.

Сног, Y. "Managerial Incentive Contracts with a Production Externality.” Economics Letters, Vol. 42 (1993), pp. $37-42$.

De Bettignies, J.E. And Ross, T. "Public-Private Partnerships and the Privatization of Financing: An Incomplete Contracts Approach.” International Journal of Industrial Organization, Vol. 27 (2009), pp. 358-368.

Dequiedt, V. And Martimort, D. "Delegated Monitoring versus Arm's-Length Contracting." International Journal of Industrial Organization, Vol. 22 (2004), pp. 951-981.

Engel, E., Fischer, R., And Galetovic, A. "The Basic Public Finance of Public-Private-Partnerships.” Forthcoming in The Journal of the European Economic Association.

Estache, A. AND Wren-Lewis, B. “Towards a Theory of Regulation for Developing Countries: Following Jean-Jacques Laffont's Lead.” Journal of Economic Literature, Vol. 47 (2009), pp. 730-771.

Francesconi, M. AND Muthoo, A. "Control Rights in Complex Partnerships." IZA Discussion Paper, University of Bonn, 2006.

Gilbert, R. AND Riordan, M. "Regulating Complementary Products: A Comparative Institutional Analysis.” The RAND Journal of Economics, Vol. 26 (1995), pp. 243-256.

HaRT, O. "Incomplete Contracts and Public Ownership: Remarks and an Application to Public-Private Partnerships." Economic Journal, Vol. 119 (2003), pp. 69-76.

HM TREASURY. Strengthening Long-Term Partnerships. London: HM Treasury, 2006.

—. Standardisation of PFI Contracts, Version 4. London: HM Treasury, 2007.

HolmströM, B. “Moral Hazard and Observability.” Bell Journal of Economics, Vol. 10 (1979), pp. 74-91. AND Milgrom, P. “Aggregation and Linearity in the Provision of Intertemporal Incentives.” Econometrica, Vol. 55 (1987), pp. 303-328.

_ AND — . "Multi-Task Principal-Agent Analyses: Incentive Contracts, Asset Ownership, and Job Design." Journal of Law, Economics and Organization, Special Issue (1991), pp. 24-52. 
House of Lords. Private Finance Projects and Off Balance Sheet Debt. London: The Stationery Office, 2010.

Institute of Public Policy Research (IPPR). Building Better Partnerships. London: Institute for Public Policy Research, 2001.

Iossa, E. And Martimort, D. "The Simple Micro-Economics of Public-Private Partnerships.” Mimeo, Paris School of Economics and University of Rome Tor Vergata, 2008.

Iтон, H. “Coalitions, Incentives, and Risk Sharing.” Journal of Economic Theory, Vol. 62 (1993), pp. 410-427.

King, S. And Pitchford, R. "Private or Public? A Taxonomy of Optimal Ownership and Management Regimes." Mimeo, University of Melbourne, 2001.

LAfFont, J.J., Regulation and Development. Cambridge: Cambridge University Press, 2005.

— AND MARTIMORT, D. “Collusion and Delegation.” The RAND Journal of Economics, Vol. 29 (1998), pp. $280-305$.

— AND —. The Theory of Incentives: The Principal-Agent Model. Princeton, NJ: Princeton University Press, 2002.

LeAhy, P. "Lessons from the Private Finance Initiative in the United Kingdom.” European Investment Bank Papers, 2005.

Lewis, T. And SAPPIngton, D. "Optimal Capital Structure in Agency Relationships." The RAND Journal of Economics, Vol. 26 (1995), pp. 343-361.

LI, S. "Bundling Decisions in Procurement Auctions with Sequential Tasks." Mimeo, Toulouse School of Economics, 2011.

Macho-Stadler, I. and Perez-Castrillo, D. "Moral Hazard with Several Agents: The Gains from Cooperation." International Journal of Industrial Organization, Vol. 11 (1993), pp. 73-100.

Martimort, D. "An Agency Perspective on the Costs and Benefits of Privatization." Journal of Regulatory Economics, Vol. 30 (2006), pp. 5-44.

— And Pouyet, J. "Build It Not: Normative and Positive Theories of Public-Private Partnerships." International Journal of Industrial Organization, Special Issue on PPPs, Vol. 26 (2008), pp. 393-411.

— And Sand-Zantman, W. "Signalling and the Design of Delegated Management Contracts for Public Utilities." RAND Journal of Economics, Vol. 37 (2007), pp. 763-782.

MOODY'S. “Operating Risk in Privately-Financed Public Infrastructure (PFI/PPP/P3) Projects.” Mimeo, 2007.

MoOKherJeE, D. AND Tsumagari, M. “The Organization of Supplier Networks: Effects of Delegation and Intermediation.” Econometrica, Vol. 72 (2004), pp. 1179-1219.

Myerson, R. "Optimal Coordination Mechanisms in Generalized Principal-Agent Problems." Journal of Mathematical Economics, Vol. 10 (1982), pp. 67-81.

National Audit Office (NAO). Operational Performance of Prisons. HC700. London: National Audit Office, 2003.

- London Underground: Were They Good Deals? HC645. London: National Audit Office, 2004.

- Improving the PFI Tendering Process. HC149. London: National Audit Office, 2007.

PARTNERSHIP U.K. (PUK). Investigating the Performance of Operational PFI contracts. London: Ipsos MORI, 2008.

Ramakrishnan, R. AND ThaKor, A. "Cooperation versus Competition in Agency." Journal of Law, Economics and Organization, Vol. 7 (1991), pp. 248-283.

Rosenkranz, S. And Schmitz, P. "Optimal Allocation of Ownership Rights in Dynamic R\&D Alliances." Games and Economic Behaviour, Vol. 43 (2003), pp. 153-173.

SAPPington, D. And Stiglitz, J. "Privatization, Information and Incentives." Journal of Policy Analysis and Management, Vol. 6 (1987), pp. 567-582.

SERCO Institute. "What Gets Measured: Contracting for Delivery." Mimeo, The Serco Institute, 2007.

SEVERINOV, S. "The Value of Information and Optimal Organization." The RAND Journal of Economics, Vol. 39 (2008), pp. 238-265.

Shapiro, C. And WiLlig, R. "Economic Rationales for the Scope of Privatization.” In E. Suleiman and J. Waterbury, eds., The Political Economy of Public Sector Reform and Privatization, pp. 55-87. Boulder, CO: Westview Press, 1990.

Shleifer, A. "State versus Private Ownership.” Journal of Economic Perspectives, Vol. 12 (1998), pp. 133-150.

Yescombe, E. Public Private Partnerships: Principles of Policy and Finance. London: Elsevier, 2007. 